\title{
Plastome structure and adaptive evolution of Calanthe s.I. species
}

\author{
Yan-Qiong Chen ${ }^{1,2}$, Hui Zhong ${ }^{1,2}$, Ya-Ting Zhu ${ }^{1,2}$, Yuan-Zhen Huang ${ }^{1,2}$, Sha-Sha Wu ${ }^{1,2}$, Zhong-Jian Liu ${ }^{1,2}$, Si-Ren \\ Lan ${ }^{\text {Corresp., }, 2, \text {, Jun-Wen Zhai }}{ }^{\text {Corresp. 1, } 2}$ \\ 1 \\ ${ }^{1}$ Key Laboratory of National Forestry and Grassland Administration for Orchid Conservation and Utilization at College of Landscape Architecture, Fujian \\ Agriculture and Forestry University, Fuzhou, Fujian, China \\ 2 Fujian Ornamental Plant Germplasm Resources Innovation \& Engineering Application Research Center, Fujian Agriculture and Forestry University, \\ Fuzhou, Fujian, China \\ Corresponding Authors: Si-Ren Lan, Jun-Wen Zhai \\ Email address: Ikzx@fafu.edu.cn, zhai-jw@163.com
}

Calanthe s.l. is the most diverse group in the tribe Collabieae (Orchidaceae), which are pantropical in distribution. Illumina sequencing followed by de novo assembly was used in this study, and the plastid genetic information of Calanthe s.I. was used to investigate the adaptive evolution of this taxon. Herein, the complete plastome of five Calanthe s.I. species (Calanthe davidii, Styloglossum lyroglossa, Preptanthe rubens, Cephalantheropsis obcordata, and Phaius tankervilliae) were determined, and the two other published plastome sequences of Calanthe s.I. were added for comparative analyses to examine the evolutionary pattern of the plastome in the alliance. The seven plastomes ranged from $150,181 \mathrm{bp}$ (C. delavayi) to $159,014 \mathrm{bp}$ (C. davidii) in length and were all mapped as circular structures. Except for the three $n d h$ genes ( $n d h C, n d h F$, and $n d h K$ ) lost in $C$. delavayi, the remaining six species contain identical gene orders and numbers (115 gene). Nucleotide diversity was detected across the plastomes, and we screened 14 mutational hotspot regions, including 12 non-coding regions and two gene regions. For the adaptive evolution investigation, three species showed positive selected genes compared with others, C. obcordata (cemA), S. lyroglossa (infA, ycf1 and ycf2) and C. delavayi (nad6 and $n d h B$ ). Six genes were under site-specific positive selection in Calanthe s.l., namely, $a c c D$, $n d h B, n d h D, r p o C 2, y c f 1$, and $y c f 2$, most of which are involved in photosynthesis. These results, including the new plastomes, provide resources for the comparative plastome, breeding, and plastid genetic engineering of orchids and flowering plants. 


\section{Plastome structure and adaptive evolution of Calanthe s.l. 2 species}

5 Yan-Qiong Chen ${ }^{1,2}$, Hui Zhong ${ }^{1,2}$, Ya-Ting Zhu ${ }^{1,2}$, Yuan-Zhen Huang ${ }^{1,2}$, Sha-Sha Wu ${ }^{1,2}$, Zhong6 Jian Liu ${ }^{1,2}$, Si-Ren Lan ${ }^{1,2}$ and Jun-Wen Zhai ${ }^{1,2^{*}}$

$8{ }^{1}$ Key Laboratory of National Forestry and Grassland Administration for Orchid Conservation 9 and Utilization at College of Landscape Architecture, Fujian Agriculture and Forestry

10 University, Fuzhou, China

$11{ }^{2}$ Fujian Ornamental Plant Germplasm Resources Innovation \& Engineering Application

12 Research Center, Fujian Agriculture and Forestry University, Fuzhou, China

13

14 Corresponding Author:

15 Jun-Wen Zhai ${ }^{1,2}$

16 No.15 Shangxiadian Road, Cangshan District, Fuzhou City, Fujian Province, 350002, China

17 Email address: zhai-jw@163.com 
18

19

20

21

22

23

24

25

26

27

28

29

30

31

32

33

34

35

36

37

38

39

40

41

42

43

44

45

46

47

48

49

50

51

52

53

54

55

\section{Abstract}

Calanthe s.1. is the most diverse group in the tribe Collabieae (Orchidaceae), which are pantropical in distribution. Illumina sequencing followed by de novo assembly was used in this study, and the plastid genetic information of Calanthe s.l. was used to investigate the adaptive evolution of this taxon. Herein, the complete plastome of five Calanthe s.1. species (Calanthe davidii, Styloglossum lyroglossa, Preptanthe rubens, Cephalantheropsis obcordata, and Phaius tankervilliae) were determined, and the two other published plastome sequences of Calanthe s.l. were added for comparative analyses to examine the evolutionary pattern of the plastome in the alliance. The seven plastomes ranged from $150,181 \mathrm{bp}$ (C. delavayi) to 159,014 bp (C. davidii) in length and were all mapped as circular structures. Except for the three $n d h$ genes $(n d h C, n d h F$, and $n d h K$ ) lost in C. delavayi, the remaining six species contain identical gene orders and numbers (115 gene). Nucleotide diversity was detected across the plastomes, and we screened 14 mutational hotspot regions, including 12 non-coding regions and two gene regions. For the adaptive evolution investigation, three species showed positive selected genes compared with others, C. obcordata (cemA), S. lyroglossa (infA, ycfl and ycf2) and C. delavayi (nad6 and $n d h B)$. Six genes were under site-specific positive selection in Calanthe s.1., namely, accD, $n d h B, n d h D, \operatorname{rpo} C 2, y c f 1$, and $y c f 2$, most of which are involved in photosynthesis. These results, including the new plastomes, provide resources for the comparative plastome, breeding, and plastid genetic engineering of orchids and flowering plants.

\section{Introduction}

Orchidaceae is the largest family in angiosperms (ca. 736 genera, ca. 28,000 species; Chase et al. 2015; Christenhusz \& Byng, 2016), with its fascinating biodiversity attracting the interest of numerous botanists. The first plastome of orchids (Phalaenopsis aphrodite) was published in 2006 (Chang et al., 2006). In total, over 200 plastomes of orchids have been published, including five subfamilies and 51 genera. In general, plastomes are relatively conserved in land plants, but huge divergence was found among different orchid species. Orchids encompass all life forms of plants, including both heterotrophic and autotrophic species, namely, terrestrial, epiphytic, and saprophytic (also called mycoheterotrophic). The evolutionary direction of the life forms of orchids can be roughly outlined from terrestrial to epiphytic, while saprophytic species independently evolved several times (Sosa et al., 2016). Recent plastome analysis of orchid species has focused on comparisons with partially and fully mycoheterotrophic species (Feng et al., 2016; Barrett \& Kennedy, 2018; Unruh et al., 2018; Yuan et al., 2018). The molecular information on these species is of interest not only for the study of phylogenetics but also for evolutionary studies and species conservation.

Calanthe, the largest genus of the Collabieae tribe (Epidendroideae, Orchidaceae), has a pantropical distribution, being widely distributed in tropical and subtropical Asia, Australia, Madagascar, Africa, Central and South America, and the Caribbean (Chen et al., 2009; Clayton 


\section{1}

82

and Cribb, 2013). Since the establishment of Calanthe in 1821 (Ker Gawler, 1821), the genus has undergone multiple intra-generic taxonomic revisions lasting for centuries. For example, Lindley (1855) set two subgenera according to the spur length, Bentham (1881) and Pridgeon et al (2005) defined the genus with different criteria based on the pseudobulb and floral characteristics. For the taxonomic classification, morphological data are limited. Genetic information suggests that the origin of Calanthe is polyphyletic and includes its relatives (Cephalantheropsis and Phaius) (Yukawa \& Ishida, 2008; Xiang et al., 2014; Zhai et al., 2014). The redefinition of the three genera seems inevitable, and Calanthe may be subdivided into three genera, Calanthe, Styloglossum, and Preptanthe (Yukawa \& Cribb, 2014; Zhai et al., 2014). These genera, Calanthe, Phaius, Styloglossum, Cephalantheropsis and Preptanthe, form an independent alliance (which we refer to as Calanthe s.1.) within Epidendroideae (Orchidaceae). This alliance can be easily distinguished from other taxa in this family, characterized by plicate leaves, similar sepals and petals, and eight waxy pollinia. However, the latest Orchidaceae classification retained the independent genus status of polyphyly Calanthe (Chase et al., 2015). To better understand their phylogenetic relationship, it is necessary for us to identify discrepancies in the genetic information of the major clade of Calanthe s.1.

In the current study, we assembled and annotated the plastomes of five Calanthe s.1. species for the first time. Additionally, we published and compared Calanthe s.l. plastome with the aim to: (1) understand the genetic variation within the Calanthe s.l. plastome; (2) identify the characteristics of the plastomes structure, sequence divergence, mutational hotspot regions, repeat regions, and examine them as candidate molecular markers for species classification and further species evolution studies; (3) assess the selective pressure among Calanthe s.l. species by identifying genes underlying positive selection; and (4) evaluate the phylogenetic relationships within Calanthe s.l.

\section{Materials \& Methods}

\section{Plant Materials, DNA Extraction and Sequencing}

Specimens of five species, Calanthe davidii, Styloglossum lyroglossa, Preptanthe rubens, Phaius tankervilliae, and Cephalantheropsis obcordate, represent the five major clades of the Calanthe s.l. (according to the phylogenetic relationship detected by Zhai et al. (2014)) and they all introduced and cultivated in the Fujian Agriculture and Forestry University, Fujian province, China. Their voucher information is given in Table S1. The modified version of the CTAB method (Doyle \& Doyle, 1987) was applied to extract the genomic DNA. We constructed the short-insert (500 bp) pair-end (PE) library and the sequencing was conducted by the Beijing Genomics Institute (Shenzhen, China) on the Illumina HiSeq 2500 platform, with a read length of $150 \mathrm{bp}$. At least $5 \mathrm{~Gb}$ clean data were obtained for each species. 


\section{Genome Assembling and Annotation}

93 We used the GetOrganelle pipe-line (Jin et al., 2019) to obtain plastid-like reads, with 18 orchid species as references (listed in Table S2). Then, the filtered reads were assembled using SPAdes version 3.1.0 (Bankevich et al., 2012). The final plastid-like reads were filtered by the script of GetOrganelle to obtain pure plastid contigs, and the filtered De Brujin graphs were viewed and edited using Bandage (Wick et al., 2015) to manually finalize the complete target genomes. DOGMA (Wyman et al., 2004) was used to annotate the plastome, a web-based package based on BLAST searches against a custom database that can identify various genes. Then, we used Geneious prime v2019.03 (Kearse et al., 2012) to manually align the results, and we examined and confirmed the plastomes with $C$. triplicata as the reference. OrganellarGenomeDRAW (OGDRAW) version 1.3.1 (https://chlorobox.mpimpgolm.mpg.de/OGDraw.html) (Greiner et al., 2019) was used to visualize the structural features of the seven species.

\section{Genome Comparison and Analysis}

Combined with two published Calanthe plastome (C. triplicata KF753635 and C. delavayi, MK388860), seven complete plastomes of Calanthe s.l. provided the possibility of comparative analysis within the relatives. In addition, We also compared the two plastome-assembled versions of $C$. davidii (D1, MG708353) and $C$. davidii (D2, assembled in the present study). Mauve alignment (Darling et al., 2004) was employed to analyse the plastome DNA rearrangement of seven species. The junction regions between the IR, SSC, and LSC of seven species were compared using the online program IRscope (https://irscope.shinyapps.io/irapp/) (Amiryousefi et al., 2018). Meanwhile, the sequence identity of the seven species were compared and plotted using the program mVISTA (http://genome.lbl.gov/vista/mvista/submit.shtml) with Shuffle-LAGAN (Brudno et al., 2003; Frazer et al., 2004) with C. triplicata (KF753635) as reference to show inter- and intraspecific variations.

To identify the mutational hotspot regions and genes, we calculated nucleotide diversity $(\pi)$ across the whole plastome. 76 CDS and 56 IGS shared by seven species were used for analysing and were extracted by PhyloSuit (Zhang et al., 2019). Seven plastome sequences were aligned using MAFFT v7.407 (Katoh \& Standley, 2013) and the nucleotide diversity $(\pi)$ was detected using DnaSP v6.12.03 (DNA Sequences Polymorphism) (Rozas et al., 2017) with sliding window strategy. The step size was set to $200 \mathrm{bp}$, with a $600 \mathrm{bp}$ window length.

\section{Repeat Sequence Analysis}

The online software REPuter (https://bibiserv.cebitec.uni-bielefeld.de/reputer/) was used to identify the repeat sequences (Kurtz et al., 2001), including palindromic direct and reverse repeats. The parameters were set as follows: (1) The maximum and minimum computed repeat sizes were limited to 50 and 30, respectively; (2) Hamming distance of 3. Tandem repeat sequences were identified with the tandem repeats finder (Benson, 1999). The alignment parameters were set as 2 match, 7 mismatch, and 7 indels. We identified repeats with condition of 80 minimum alignment score, maximum period sizes in $500 \mathrm{bp}$, and maximum TR array sizes 
131 of 2 million. Perl script MISA (MIcroSAtellite identification tool) was used to detect simple

132 sequence repeats (SSRs) loci of the plastome, with a threshold of mono-, di-, tri-, tetra-, penta-,

133 and hexa-nucleotide SSRs, respectively (Thiel et al., 2003).

\section{Gene Selection Pressure Analysis}

135 To identify the gene divergences changes within seven species, nonsynonymous (Ka) and 136 synonymous substitution rates $(\mathrm{Ks})$, and the ratio $\mathrm{Ka} / \mathrm{Ks}$ were calculated using the

137 KaKs_calcaulator (Wang et al., 2010). We analysed all CDS gene regions (76 genes), except for $138 n d h C, n d h F$ and $n d h K$ as these regions were lost in $C$. delavayi, and $y c f 15$ as pseudogenes in $S$.

139 lyroglossa and $P$. rubens. The seven species pairwise comparison generated 21 species pairs in

140 total. The parameters were set as genetic code table 11 (bacterial and plant plastid code), method

141 of calculation YN. When the genes had no substitutions on the alignment or there was $100 \%$

142 match, the Ks value was set as 0 ; in this case, the $\mathrm{Ka} / \mathrm{Ks}$ value was shown as "NA" in the results.

143 We replaced all "NA" results with 0.

144 We also evaluated the role of site-specific selection in 76 genes of seven species. The

145 maximum likelihood tree was constructed based on the aligned concatenated CDS genes data set

146 of the seven species using IQ-tree (Nguyen et al., 2105). We calculated the nonsynonymous (dN)

147 substitution, synonymous (dS) substitution rates, and the $\mathrm{dN} / \mathrm{dS}$ ratio $(\omega)$ in order to estimate the

148 selection pressure with site-specific model (the option of the analyses was set to seqtype $=1$,

149 model $=0$, and Nssites $=0,1,2,3,7$, and 8) with CodeML program in PAML 4.9 (Yang and

150 Nielsen, 2002; Yang, 2007). The likelihood ratio tests (LRTs) P-values of under three pairs of

151 site models were calculated to detect positive selection $(\mathrm{p}<0.05)$, including: M0 (one-ratio) vs.

152 M3 (discrete), M1 (nearly neutral) vs. M2 (positive selection), and M7 ( $\beta$ ) vs. M8 ( $\beta$ and $\omega$ ).

\section{Phylogenetic Analysis}

154 Phylogenetic analysis was conducted using plastome sequences of the seven Calanthe s.1. taxa 155 mentioned above, with Bletilla striata (GenBank accession No. KT588924) used as an outgroup.

156 We generated four data sets for phylogenetic inference: (1) complete plastome sequences; (2) 157 coding regions (CDS); (3) intergenic regions (IGS); and (4) 13 highly variable regions screened

158 in the present study (nad6 gene was lost in Bletilla striata, so nad6-ndhI was excluded in the

159 analysis). We extracted the 76 CDS and 46 IGS shared by eight species from plastomes using 160 PhyloSuit (Zhang et al., 2019). MAFFT v7.107 (Katoh \& Standley, 2013) was conducted for 161 sequence alignments.

162 A maximum likelihood (ML) tree was constructed using IQ-tree with 1,000 bootstrap 163 replicates. The optimal nucleotide substitution model was found with ModelFinder module in 164 IQ-tree (Nguyen et al., 2015). Bayesian inference (BI) was performed with Mrbayes v3.2

165 (Ronquist et al., 2012). The Markov chain Monte Carlo (MCMC) analysis was run for

$16650,000,000$ generations. The stationarity was regarded as having been reached when the average

167 standard deviation of split frequencies remained below 0.01 . Trees were sampled at every 1,000

168 generations with the first $25 \%$ discarded as burn-in. The remaining trees were used to build a

$16950 \%$ majority-rule consensus tree. 


\section{Results}

\section{Features of the Plastome}

173 We reassembled and annotated the plastome of $C$. davidii (we use the abbreviations D1

174 (MG925365) and D2 (MN708353) to represent the different versions of the C. davidii plastome).

175 In the present study, the reassembled version of $C$. davidii (D2) is hugely different from the

176 published plastome. A comparison between these two genomes indicated that the gene numbers

177 and orders are identical, while huge differences were found in the genome size, gene length, and

178 GC content (Tables 1 and 2). We used the D2 version of $C$. davidii for the subsequent analysis.

179 The genome size of D1 is 5,385 bp shorter than D2, with the difference mainly concentrated

180 in the IR region, especially $n d h$ genes, which encode the subunits of the nicotinamide adenine

181 dinucleotide (NADH) dehydrogenase-like complex proteins (Yamori \& Shikanai, 2016). The

182 assembling and annotating of D1 used Dendrobium nobile as the reference (Dong et al., 2018),

183 which has a discrepancy with $C$. triplicata we used as reference in this study, especially $n d h$,

184 e.g., the $n d h C$, $n d h I, n d h K$, and nad6 genes were lost in D. nobile but exist in C. triplicata.

185 Moreover, D. nobile showed a distant relationship with C. davidii, Dendrobium belong to

186 Malaxideae tribe were far away from the Collabieae tribe, to which $C$. davidii belongs (Chase et

187 al., 2015). Considering the conservatism of the plastome, and the reasons mentioned above, we

188 may infer that the results of this study are more accurate.

189 The plastome of the seven species of Calanthe s.l. ranged from 150,181 bp (C. delavayi) to

190159,014 bp (C. davidii, D1), with a GC content of 36.60\%-37.00\% (Table 1). They all shared

191 the common structure: a pair of IRs (IRa and IRb) (25,216-26,617 bp), separated by LSC region

192 (83,411-87,857 bp) and SSC region (16,338-18,589 bp) (Table 1 and Fig. 1). The gene

193 numbers, orders, and names were very similar among Calanthe s.1., except for the three gene

194 losses of $C$. delavayi, namely, $n d h C, n d h F$, and $n d h K$ (Figs. 2, 3, 4).

195 The genomes encoded 133-136 genes, of which 112-115 were unique genes, containing

196 77-80 protein-coding genes, 30 tRNA genes, and four rRNA genes. Two pseudogenes were

197 found in the seven plastomes; the $y c f 15$ was the only pseudogenization in S. lyroglossa and $P$.

198 rubens while the $y c f 68$ gene was a pseudogene in all seven species. They both contain many

199 internal stop codons. The 18 genes were found duplicated in the IR regions, including three type

200 of genes, namely, coding genes, tRNA genes and rRNA genes (Table 3). In the seven plastomes,

20115 genes contained one intron (six tRNA and nine protein-coding genes) and three genes $(y c f 3$,

202 clpP, and rps 12) contained two introns. The gene rps 12 was trans-spliced, crossing the two areas

203 with the 5'-end exon lie in the LSC region and the intron, 3'-end exon located in the IR region.

204 Overlapping sequences were found in three pair of genes: $\operatorname{trnK}$-UUU/matK, atpE/atpB, and

$205 \mathrm{ps} b D / p s b C$. 
206

207

208

209

210

211

212

213

214

215

216

217

218

219

220

221

222

223

224

225

226

227

228

229

230

231

232

233

234

235

236

237

238

239

\section{Comparative Genomic Analysis}

The seven plastome sequence identities were plotted using mVISTA and with C. triplicata (KF753635) as reference. The alignment revealed high sequence similarity across the seven plastomes and no rearrangement occurred (Figures 2 and 3) which suggested that they are highly conserved. The SSC region has the highest divergence $(\pi=0.0187)$ while IR region is the most conservative $(\pi=0.0036)$ (Table S3). We chose the nine mutational hotspots according to the sequence divergence analysis (nucleotide diversity $(\pi>0.03)$, including 12 regions (atpBrbcL ccsA-ndhD, clpP-psbB, nad6-ndhI, psbA-matK, psbB-psbT, rpl32-trnL-UAG, rps11-rpl36infA, rps 16-trnQ-UUG, trnE-UUC-trnM-CAU, $\operatorname{trn} F$-GAA- $n d h J$, $\operatorname{trn} S$-UGA-trnG-GC), and two gene regions (trnK-UUU, $c l p P$ ) (Figs. 3 and 4).

We examined the expansion and contraction of the IR area between the single-copy regions and the pair of IR regions for the seven Calanthe s.1. species (Fig. 5). Among the seven species, the gene positions of four borders (LSC/IRb, IRb/SSC, SSC/IRa, and IRa/LSC) had different types. The LSC/IRb border had three situations. First, in C. triplicata, C. delavayi, $P$. tankervilliae, and C. obcordata, the rpl22 gene overlapped in the LSC/IRb region; second, in $C$. davidii and S. lyroglossa the rpl22 gene was located in the LSC region, 9-47 bp away from the $\mathrm{IRb}$ region; the third situation is in P. rubens, where the rps 19 gene overlapped the border instead of the $r p l 22$ gene. While the IRb/SSC junction regions were relatively stable in the seven species, the $n d h F$ gene crossed the border of six of the seven species, except for $C$. delavayi, due to its $n d h F$ gene loss, and the nearest gene $(\operatorname{trn} N$ (in IRb)) is $361 \mathrm{bp}$ away from the SSC region. $\mathrm{SSC} / \mathrm{IRa}$ and IRa/LSC are both very conserved among the seven plastomes. The $y c f 1$ gene strode the SSC/IRa bounder, having 35-1042 bp into the IRa region. The distance between $p s b A$ and the IRa/LSC junction ranged from 91 to $239 \mathrm{bp}$.

Repeats in the plastome were detected. P. rubens had the greatest number of long repeats and $C$. triplicata had the greatest number of tandem repeat regions (Tables S4 and S5). A total number of 49-73 SSRs were found in the seven plastomes. Mononucleotide, dinucleotide, trinucleotide, tetranucleotide, and pentanucleotide SSRs were all discovered in seven Calanthe s.1. species (Fig. 6). Hexanucleotide SSRs were found except in C. davidii and P. rubens. In all seven species, mononucleotide repetitions accounted for more than half of all $(57.89 \%, 56.67 \%$, $54.79 \%, 61.22 \%, 54.68 \%, 53.73 \%$, and $60 \%$ ). The IGS region contained the largest number of SSRs (with 231 identified), while 175 were identified in the CDS and 64 in the coding sequence introns. In particular, all mononucleotide SSRs belonged to A or T types, and the richness of A or $\mathrm{T}$ were found in the major of dinucleotide, trinucleotide, tetranucleotide, pentanucleotide, and hexanucleotide SSRs (Table S6).

\section{Gene Selection Pressure Analysis of Protein Sequences}

The average $\mathrm{Ka} / \mathrm{Ks}$ ratio for 76 protein-coding genes analysed in the seven genomes was 0.2455 . We found the 13 most conserved genes with average $\mathrm{Ka} / \mathrm{Ks}$ values between 0 and 0.01 , pet $G, p s a C, p s b E, p s b I, p s b J, p s b l, p s b N, p s b T, r p l 23, r p l 36, r p s 12, r p s 19$ and $r p s 7$. These genes are under very strong purifying selection pressure. Values of $\mathrm{Ka} / \mathrm{Ks}$ in the range of 0.5 to 1.0 (indicating relaxed selection) were observed for the genes $m a t K, a t p F, r p o C 2, a c c D, r p s 18$, 
$246 r p o A$, ndhD, ndhI and rps 15 . We found six protein-coding genes with $\mathrm{Ka} / \mathrm{Ks}>1$, including cem $A$

247 (1.3680) in C. obcordata, infA (2.9934), ycf1 (1.2618) and ycf2 (1.0886) in S. lyroglossa, nad6

248 (3.0761) and $n d h B(1.4169)$ in C. delavayi (Table S7, and Fig. 7).

249

The site-specific selective pressure on seven species of Calanthe s.l. were assessed using

250

251

252

253

254

255

256

257

258

259

260

261

\section{Discussion}

263

264

265

266

267

268

269

270

271

272

273

274

275

276

277

278

279

280

281

282

283

284 the site model in the PAML program. Three pairs of site model comparisons (M0 vs. M3, M1 vs. M2a, M7 vs. M8) showed that six genes were related to two photosynthetic electron transport ( $n d h D$ and $r b c L$ ), gene expression ( $r p o c 2)$, and other functions ( $a c c D, y c f 1$ and $y c f 2$ ) had been subjected to positive selection (LRT of the three comparison all P $<0.05$ ) (Tables S8 and S9).

\section{Phylogenetic Analysis}

The phylogenetic relationship inferred by ML and $\mathrm{BI}$ analysis of the four data sets resulted in the same topology (Fig. 8). The seven Calanthe s.l. species were classified into three major clades, with all the Calanthe s.l. species composing a monophyly. Preptanthe is located at the basal position and is sister to the clade formed by the remaining other four genera.

Cephalantheropsis and Styloglossum are clustered into a sister clade to Phaius, which forms the sister group to Calanthe.

\section{Chloroplast Sequence Variation}

The whole plastome of five Calanthe s.l. species were determined, which had never been done for Phaius, Cephalantheropsis, Styloglossum and Preptanthe and was a reconstruction for $C$. davidii. Comparative analyses of the plastome of seven Calanthe s.l. species showed highly conserved structures and genes. The published Orchidaceae plastome genome size ranges from 35,304 bp (Gastrodia elata) to 178,131 bp (Cypripedium formosanum). This discrepancy in the plastome genome size can be explained by the different life forms, as the heterotrophic plants that do not photosynthesise have lost the photosynthesis-related genes. In the present study, only C. delavayi lost the $n d h$ genes ( $n d h C, F$, and $K$ ) in Calanthe s.l. It is also common to see a lack of functional $n d h$ genes in other autotrophic orchids, i.e., Cymbidium, Dendrobium, Phalaenopsis and Ophrys (Yang et al., 2013; Lin et al., 2017; Roma et al., 2018). Although the transfer of the $n d h$ genes from the plastome genome to the mitochondrial $(\mathrm{mt})$ genome was detected in some orchids, there is no direct evidence showing that these transfers were linked to the losses of $n d h$ in the plastome (Lin et al., 2015). The mechanisms for the complex deletion and truncation of the genes encoding NADH dehydrogenase subunits in orchids remain unclear.

We found two pseudogenes of the seven species, two hypothetical genes $y c f 15$ and $y c f 68$. The $y c f 15$ was first identified as ORF87 in the Nicotiana chloroplast genome (Shinozaki et al., 1986); however, the validity of the gene as protein-coding gene has been questioned (Chumley et al., 2006). It was disabled in Amoborella, Nuphar and most rosids (Goremykin et al., 2003; Raubeson et al., 2007). In some lineages it has been completely lost, for example Illicium, Acorus, Ceratophyllum, Ranunculus and some non-photosynthetic orchids (Shi et al., 2013; Yuan et al., 2018). The likelihood that the $y c f 15$ and $y c f 68$ are not protein-coding genes has been 
285 discussed in previous research (Raubeson et al., 2007). In the present study, $y c f 15$ was annotated 286 as a protein-coding gene in five other species (C. triplicata, C. davidii, C. delavayi, C. obcordata 287 and $P$. tankervilliae), because they are conserved in IR region among the different species.

288 Whether these sequences represent protein-coding regions and their possible functions in chloroplasts needs to be further studied.

Although the overall genomic structures and gene orders of Calanthe s.l. are highly conserved, significant differences at the IR/SSC junction area were detected. The different expansion and contraction situation of the IR junction area will cause the plastome size differentiation (Bock \& Knoop, 2012). In present study, among the four boundaries, only $\mathrm{LSC} / \mathrm{IRb}$ shows three types in the seven species, while the remaining three (IRb/SSC, SSC/IRa, and IRa/LSC) are conservative and stable. Because of the $n d h F$ gene loss in C. delavayi, IR contraction was detected. Previous research has pointed out that the deletion of the $n d h$ genes has great influence on the instability of the IR/SSC boundary in orchids (Kim et al., 2015; Niu et al., 2017). The position of the boundary, especially the expansion and contraction of the region, could shed light on the evolution of the lineage. However, in Calanthe s.l., our observations would not provide the information required to elucidate the evolutionary relationships of the taxa, and whether it can benefit from adaptation require further investigation; thus, additional sampling of Calanthe spp. and related genera will allow for explicit tests.

\section{Molecular Markers and Candidate SSRs}

Coding regions and conserved sequences of the plastome are widely used for phylogenetic inferences at higher taxonomic levels (family or genus) (Givnish et al., 2015; Jansen et al., 2007). Plastomes are ideal resources for selecting the mutational hotspots of various lineages and are used for intraspecies discrimination and phylogenetic studies at the species level (Ahmed et al., 2013; Liu et al., 2018). At present, some plastid DNA fragments are used in the taxonomy of Calanthe s.l., for instance $m a t K, r b c L$, and intergenic spacer $\operatorname{trnL} L$-trnF (Zhai et al., 2014; Guo et al., 2017), but they could not provide sufficient phylogeny signals to establish the high-resolution phylogeny relationship for classification of related taxa, especially some infrageneric taxa whose taxonomic classification status are unclear. Our alignment screened the top 14 loci that most likely contained the highest degrees of genetic variability in Calanthe s.l., which can be useful in species-level phylogenetic studies of Calanthe s.l.

Simple sequence repeats are short (1-5 bp) repeat motifs that are tandemly repeated for varying numbers of times (Kantety et al., 2002). Because of its extensively dispersal in genomes, they are widely utilized in population genetics and molecular evolution studies (Guichoux et al., 2002). SSRs can provide interspecific polymorphisms, which are effective markers in population genetic analysis. We identified 18 SSRs as polymeric SSRs between Calanthe s.1. species; however, further experiments are needed to verify its effectiveness (Table 4). Mutational hotspots and SSRs derived from the plastome can serve as valuable tools for elucidating the evolutionary relationships and plant identification of Calanthe s.l. 


\section{Adaptive Evolution Analysis}

324 Calanthe s.l. are pantropical in their distribution, with high geographic and ecological diversity,

325

326

327

328

329

330

331

332

333

334

335

336

337

338

339

340

341

342

343

344

345

346

347

348

349

350

351

352

353

354

355

356

357

358

359

360

361

362 from obligate epiphytic to hemi-epiphytic and terrestrial, ranging from sea level to alpine mountain areas. However, the majority live under tropical woods and forests, very often in deep shade (Clayton\& Cribb, 2013; Stone \& Cribb, 2017). To better understand the evolutionary history of these groups, the analysis of the genetic diversity and adaptive evolution of Calanthe s.l. is essential. Positive selection genes played an important part in the adaption to various environments. Within the seven species, we detected the six species-specific positive selection genes in only three species, namely, one in C. obordata (cemA), three in S. styloglossa (infA, ycfl and $y c f 2$ ), and two in $C$. delavayi ( $\operatorname{cad} 6$ and $n d h B$ ). Those identified selected genes may have undergone certain functional diversification during their evolutionary history.

cemA encodes a chloroplast envelope membrane protein (Sasaki et al., 1993) and is inferred to indirectly influence $\mathrm{CO}_{2}$ uptake in plastid (Rolland et al., 1997). In some non-photosynthetic orchids, cemA exists as pseudogene or is lost (Feng et al., 2016; Kim et al., 2020). infA is crucial for genetic information transmission that affects transcription of DNA into RNA and translation of RNA to protein; it is seen as a housekeeping gene (Schelkunov et al., 2015). Two genes with large ORFs encoding proteins of the unknown function, $y c f 1$ and $y c f 2$. nad6 gene encoding NADH-plastoquinone oxidoreductase subunit $6, n d h B$ gene encoding $\mathrm{NAD}(\mathrm{P}) \mathrm{H}$-quinone oxidoreductase subunit 2 can influence the cyclic electron flow around photosystem I (Shikanai et al., 1998). They are both NAD(P)H-plastoquinone-oxidoreductase (NDH complex) encodingrelated genes. Chloroplast $\mathrm{NAD}(\mathrm{P}) \mathrm{H}$ dehydrogenase is sensitive to strong light stress and can protect plants from photoinhibition or photooxidation stress and alleviate decreases in the photosynthetic rate and growth delay caused by drought, suggesting that the $n d h$ genes encoding the $\mathrm{NAD}(\mathrm{P}) \mathrm{H}$ dehydrogenase $(\mathrm{NDH})$ may also be involved in stress acclimation through the optimization of photosynthesis (Horváth et al., 2000; Rumeau et al., 2007). C. delavayi is one of species with the highest elevation distribution in the Calanthe s.l. (up to $3500 \mathrm{~m}$ ). The positive selection signal of $n d h B$ and nad 6 in the $C$. delavayi might be the result of adaptation to different environment with other six species.

Six genes were under positive selection in seven Calanthe s.l. species. Of these genes, one functions as a subunit of acetyl-CoA-carboxylase $(a c c D)$, two NADH dehydrogenase subunit genes ( $n d h B$ and $n d h D$ ), one RNA polymerase subunit (rpoC2), and two genes whose functions are uncertain $(y c f 1$ and $y c f 2)$. Except for the $n d h$ genes, the remaining four positively selected genes were also detected in orchid species (Dong et al., 2018), and these four genes may have played significant roles in the adaptive evolution history of Calanthe s.l. Specific roles need to be further studied.

The function of the plastid $a c c D$ gene has been reported as essential for plant leaf development (Kode et al., 2005). We detected the two positively selected sites in $a c c D$ genes for Calanthe s.l. The $n d h$ gene family in the plastome is involved in photosynthesis. The $n d h B$ and $n d h D$ genes possessed 12 and 10 positively selected sites, respectively. Although there is the viewpoint that NDH activity may not be required in some plants (Yang et al., 2013), these two 
363 genes may play important roles in the adaptation of Calanthe s.l. species to deep shade

364 environments. In addition, the rpoC2 (RNA polymerase subunit C2) gene was crucial for gene

365 transcription (Xie et al., 1989), and only one site was positively detected in our study. Plastomes

366 contain a number of uncertain genes. The $y c f s$ (hypothetical open reading frame) gene has great

367 application potential for elucidating plant phylogeny (Neubig et al., 2009; Huang et al., 2010;

368 Dong et al., 2015). As the largest genes in $y c f s, y c f 1$ and $y c f 2$ have shown positive selection in

369 one and eight sites, respectively, and the phenomenon extends to the many plant lineages,

370 including orchids (Greiner et al., 2008; Huang et al., 2010; Carbonell-Caballero et al., 2015).

371 Phylogenetic Analysis

372 Plastid sequences have been used in phylogenetic analyses based on their most nonrecombinant

373 and uniparentally inherited and on their slower evolutionary rates than nuclear and mitochondrial

374 genomes (Wolfe et al., 1987; Birky, 1995). The plastid region of $m a t K, r b c L$ and $t r n L-F$ have

375 been used as genetic markers with great success in Orchidaceae (Cameron et al., 1999; Salazar et al., 2009; Hu et al., 2020). However, the limited loci in phylogenetic inference are not powerful

377 enough when closely related species are under consideration. Phylogenetic analyses based on

378 plastome data sets have become a popular and practical approach and therefore comparative

379

380 genomic studies of more plastome sequences have become necessary.

In the present study, the relationships among seven Calanthe s.1. species all had high

381

382 support value (bootstrap support value $>90$ and Bayesian posterior probability $>0.95$ ), and they can be completely distinguished from one another (Fig. 8). The seven species were separated

383 into three evolutionary branches. The branch including $C$. davidii, $C$. triplicata and $C$. delavayi was a sister to branch containing $S$. lyroglossa, $C$. obcordata and $P$. tankervilliae, and $P$. rubens was placed at the basal position. We obtained high resolution using the nine highly variable regions with lower cost.

387

\section{Conclusions}

389

In this study, we assembled and analysed five new complete plastome sequences of Calanthe s.l. and compared them with other Calanthe species for the first time. The annotation and comparison within Calanthe s.l. species showed conservative in gene sequence, GC content and genomic composition. The repeated sequences, 18 microsatellites and 14 highly mutational hotspot regions were identified in the Calanthe s.l. plastome. Six site-specific positively selected genes were detected. These genes will lead to understanding of the adaptations of Calanthe s.l. species to deep shade environments. The study will help to resolve the phylogenetic relationships and understand the adaptive evolution of Calanthe. It will also provide genomic resources and potential markers suitable for future species identification and speciation studies of the genus. 
399

400

401

402

403

404

405

406

407

408

409

410

411

412

413

414

415

416

417

418

419

420

421

422

423

424

425

426

427

428

429

430

431

432

433

434

435

436

437

438

\section{References}

Ahmed I, Matthews PJ, Biggs PJ, Naeem M, McLenachan PA, Lockhart PJ. 2013. Identification of chloroplast genome loci suitable for high-resolution phylogeographic studies of Colocasia esculenta (L.) S chott (A raceae) and closely related taxa. Molecular Ecology Resources, 13(5):929-937. DOI 10.1111/1755-0998.12128.

Amiryousefi A, Hyvönen J, Poczai P. 2018. IRscope: an online program to visualize the junction sites of chloroplast genomes. Bioinformatics. 34(17):3030-3031. DOI 10.1093/bioinformatics/bty220.

Bankevich A, Nurk S, Antipov D, Gurevich AA, Dvorkin M, Kulikov AS, Lesin VM, Nikolenko SI, Pham S, Prjibelski AD, Pyshkin AV, Sirotkin AV, Vyahhi N, Tesler G, Alekseyev MA, Pevzner PA. 2012. SPAdes: a new genome assembly algorithm and its applications to single-cell sequencing. Journal of computational biology, 19(5):455-477. DOI 10.1089/cmb.2012.0021.

Barrett CF, Kennedy AH. 2018. Plastid genome degradation in the endangered, mycoheterotrophic, North American orchid Hexalectris warnockii. Genome biology and evolution, 10(7):1657-1662. DOI 10.1093/gbe/evy107.

Benson G. 1999. Tandem repeats finder: a program to analyze DNA sequences. Nucleic acids research, 27(2):573-580. DOI 10.1093/nar/27.2.573.

Bentham G. 1881. Notes on Orchidceae. Botanical journal of the Linnean Society. 18:281-360. DOI 10.1111/j.1095-8339.1881.tb01258.x.

Birky CW. 1995. Uniparental inheritance of mitochondrial and chloroplast genes: mechanisms and evolution. Proceedings of the National Academy of Sciences, 92(25):11331-11338. DOI 10.1073/pnas.92.25.11331.

Bock R, Knoop V. (Eds.). 2012. Genomics of chloroplasts and mitochondria (Vol. 35). Springer Science \& Business Media.

Brudno M, Malde S, Poliakov A, Do CB, Couronne O, Dubchak I, Batzoglou S. 2003. Glocal alignment: finding rearrangements during alignment. Bioinformatics, 19(suppl_1):i54i62. DOI 10.1093/bioinformatics/btg1005.

Cameron KM, Chase MW, Whitten WM, Kores PJ, Jarrell DC, Albert VA, Goldman DH. 1999. A phylogenetic analysis of the Orchidaceae: evidence from $r b c L$ nucleotide sequences. American Journal of Botany, 86(2):208-224. DOI 10.2307/2656938.

Carbonell-Caballero J, Alonso R, Ibañez V, Terol J, Talon M, Dopazo J. 2015. A phylogenetic analysis of 34 chloroplast genomes elucidates the relationships between wild and domestic species within the genus Citrus. Molecular biology and evolution, 32(8):2015-2035. DOI $10.1093 / \mathrm{molbev} / \mathrm{msv} 082$.

Chang CC, Lin HC, Lin IP, Chow TY, Chen HH, Chen WH, Cheng CH, Lin CY, Liu SM, Chang CC, Chaw SM. 2006. The chloroplast genome of Phalaenopsis aphrodite (Orchidaceae): comparative analysis of evolutionary rate with that of grasses and its phylogenetic implications. Molecular biology and evolution, 23(2):279-291. DOI 10.1093/molbev/msj029. 
439

440

441

442

443

444

445

446

447

448

449

450

451

452

453

454

455

456

457

458

459

460

461

462

463

464

465

466

467

468

469

470

471

472

473

474

475

476

Chase MW, Cameron KM, Freudenstein JV, Pridgeon AM, Salazar G, Van den Berg C, Schuiteman A. 2015. An updated classification of Orchidaceae. Botanical journal of the Linnean Society, 177(2):151-174. DOI 10.1111/boj.12234.

Chen SC, Liu ZJ, Zhu GH, Lang KY, Ji ZH, Luo YB, Jin XH, Cribb PJ, Wood JJ, Gale SW, Ormerod P, Vermeulen JJ, Wood HP, Clayton D, Bell A. 2009. Orchidaceae. In: Wu, Z.Y., Raven, P.H., Hong, D. (Eds.), Flora of China, vol. 25. Science Press, Beijing \& Missouri Botanical Garden Press, St. Louis, pp. 1-9.

Christenhusz MJ, Byng JW. 2016. The number of known plants species in the world and its annual increase. Phytotaxa, 261(3):201-217. DOI 10.11646/phytotaxa.261.3.1.

Chumley TW, Palmer JD, Mower JP, Fourcade HM, Calie PJ, Boore JL, Jansen RK. 2006. The complete chloroplast genome sequence of Pelargonium $\times$ hortorum: organization and evolution of the largest and most highly rearranged chloroplast genome of land plants. Molecular biology and evolution, 23(11):2175-2190. DOI 10.1093/molbev/msl089.

Clayton D, Cribb P. 2013. The Genus Calanthe, Natural History Publications.

Darling AC, Mau B, Blattner FR, Perna NT. 2004. Mauve: multiple alignment of conserved genomic sequence with rearrangements. Genome research, 14(7):1394-1403. DOI 10.1101/gr.2289704.

Dong WL, Wang RN, Zhang NY, Fan WB, Fang MF, Li ZH. 2018. Molecular evolution of chloroplast genomes of orchid species: Insights into phylogenetic relationship and adaptive evolution. International Journal of Molecular Sciences, 19(3):716. DOI 10.3390/ijms19030716.

Dong WP, Xu C, Li CH, Sun JH, Zuo YJ, Shi S, Cheng T, Guo JJ, Zhou SL. 2015. ycfl, the most promising plastid DNA barcode of land plants. Scientific reports, 5:8348. DOI 10.1038/srep08348.

Doyle JJ, Doyle JL. 1987. A rapid DNA isolation procedure for small quantities of fresh leaf tissue. Phytochemical Bulletin, 19:11-15. DOI 10.1016/j.bse.2009.07.003.

Feng YL, Wicke S, Li JW, Han Y, Lin CS, Li DZ, Zhou TT, Huang WC, Huang LQ, Jin XH. 2016. Lineage-specific reductions of plastid genomes in an orchid tribe with partially and fully mycoheterotrophic species. Genome biology and evolution, 8(7):2164-2175. DOI 10.1093/gbe/evw144.

Frazer KA, Pachter L, Poliakov A, Rubin EM, Dubchak I. 2004. VISTA: computational tools for comparative genomics. Nucleic acids research, 32(suppl_2):W273-W279. DOI 10.1093/nar/gkh458.

Givnish TJ, Spalink D, Ames M, Lyon SP, Hunter SJ., Zuluaga A, Iles WJD, Clements MA, Arroyo MTK, Leebens-Mack J, Endara L, Kriebel R, Neubig KM, Whitten WM, Williams NH, Cameron, KM. 2015. Orchid phylogenomics and multiple drivers of their extraordinary diversification. Proceedings of the Royal Society B: Biological Sciences, 282(1814):20151553. DOI 10.1098/rspb.2015.1553. 
477 Goremykin VV, Hirsch-Ernst KI, Wölfl S, Hellwig FH. 2003. Analysis of the Amborella

478

479

480

481

482

483

484

485

486

487

488

489

490

491

492

493

494

495

496

497

498

499

500

501

502

503

504

505

506

507

508

509

510

511

512

513

514

515

516

trichopoda chloroplast genome sequence suggests that Amborella is not a basal angiosperm. Molecular biology and evolution, 20(9):1499-1505. DOI 10.1093/molbev/msg159.

Greiner S, Lehwark, P, Bock R. 2019. OrganellarGenomeDRAW (OGDRAW) version 1.3. 1: expanded toolkit for the graphical visualization of organellar genomes. Nucleic Acids Research, 47(W1):W59-W64. DOI 10.1093/nar/gkz238.

Greiner S, Wang X, Rauwolf U, Silber MV. Mayer K, Meurer J, Haberer G, Herrmann RG. 2008. The complete nucleotide sequences of the five genetically distinct plastid genomes of Oenothera, subsection Oenothera: I. Sequence evaluation and plastome evolution. Nucleic acids research, 36(7):2366-2378. DOI 10.1093/nar/gkn081.

Guichoux E, Lagache L, Wagner S, Chaumeil P, Léger P, Lepais O, Lepais O, Lepoittevin C, Malausa T, Revardel E, Salin F, Petit RJ. 2011. Current trends in microsatellite genotyping. Molecular ecology resources, 11(4):591-611. DOI 10.1111/j.17550998.2011.03014.x.

Guo M, Zhai JW, Wu XY, Li SX, Wang M, Li ZJ, Chen LJ. 2017. Calanthe taibaishanensis, a new orchid species from China: Evidence from morphological and molecular analyses. Phytotaxa, 327(2):184-190. DOI 10.11646/phytotaxa.327.2.7.

Horváth EM, Peter SO, Joët T, Rumeau D, Cournac L, Horváth GV, Kavanagh TA, Schäfer C, Peltier G, Medgyesy P. 2000. Targeted inactivation of the plastid $n d h B$ gene in tobacco results in an enhanced sensitivity of photosynthesis to moderate stomatal closure. Plant Physiology, 123(4):1337-1350. DOI 10.1104/pp.123.4.1337.

Hu AQ, Gale SW, Liu ZJ, Suddee S, Hsu TC, Fischer GA, Saunders RM. 2020. Molecular phylogenetics and floral evolution of the Cirrhopetalum alliance (Bulbophyllum, Orchidaceae): Evolutionary transitions and phylogenetic signal variation. Molecular Phylogenetics and Evolution, 143:106689. DOI 10.1016/j.ympev.2019.106689.

Huang JL, Sun GL, Zhang DM. 2010. Molecular evolution and phylogeny of the angiosperm ycf2 gene. Journal of Systematics and Evolution, 48(4):240-248. DOI 10.1111/j.17596831.2010.00080.x.

Jansen RK, Cai Z, Raubeson LA, Daniell H, dePamphilis CW, Leebens-Mack J, Müller KF, Guisinger-Bellian M, Haberle RC, Hansen AK, Chumley TW, Lee S, Peery R, McNeal JR, Kuehl JV, Boore JL. 2007. Analysis of 81 genes from 64 plastid genomes resolves relationships in angiosperms and identifies genome-scale evolutionary patterns. Proceedings of the National Academy of Sciences, 104(49):19369-19374. DOI 10.1073/pnas.0709121104.

Jin JJ, Yu WB, Yang JB, Song Y, dePamphilis CW, Yi TS, Li DZ. 2019. GetOrganelle: a fast and versatile toolkit for accurate de novo assembly of organelle genomes. BioRxiv, 256479. DOI 10.1101/256479.

Kantety RV, La Rota M, Matthews DE, Sorrells ME. 2002. Data mining for simple sequence repeats in expressed sequence tags from barley, maize, rice, sorghum and wheat. Plant molecular biology, 48(5-6):501-510. DOI 10.1023/A:1014875206165.

Peer) reviewing PDF | (2020:05:49446:1:1:NEW 21 Aug 2020) 
517 Katoh K, Standley DM. 2013. MAFFT multiple sequence alignment software version 7:

518 improvements in performance and usability. Molecular biology and evolution, 30(4):772-780.

$519 \quad$ DOI 10.1093/molbev/mst010.

520

521

522

523

524

525

526

527

528

529

530

531

532

533

534

535

536

537

538

539

540

541

542

543

544

545

546

547

548

549

550

551

552

553

554

555

Kearse M, Moir R, Wilson A, Stones-Havas S, Cheung M, Sturrock S, Buxton S, Cooper A, Markowitz S, Duran C, Thierer T, Ashton B, Meintjes P, Drummond A. 2012. Geneious Basic: an integrated and extendable desktop software platform for the organization and analysis of sequence data. Bioinformatics, 28(12):1647-1649. DOI 10.1093/bioinformatics/bts199.

Ker Gawler, JB. 1821. Botanical Register, Consisting of Coloured Figures of Exotic Plants Cultivated in British Gardens, with their History and Mode of Treatment, In, sub t, London, Vol. 7, p. 573.

Kim HT, Kim JS, Moore MJ, Neubig KM, Williams NH, Whitten WM, Kim JH. 2015. Seven new complete plastome sequences reveal rampant independent loss of the ndh gene family across orchids and associated instability of the inverted repeat/small single-copy region boundaries. PLoS One, 10(11):e0142215. DOI 10.1371/journal.pone.0142215.

Kim YK, Jo S, Cheon SH, Joo MJ, Hong JR, Kwak M, Kim KJ. 2020. Plastome Evolution and Phylogeny of Orchidaceae, With 24 New Sequences. Frontiers in Plant Science, 11:22. DOI 10.3389/fpls.2020.00022.

Kode V, Mudd EA, Iamtham S, Day A. 2005. The tobacco plastid $a c c D$ gene is essential and is required for leaf development. The plant journal, 44(2):237-244. DOI 10.1111/j.1365313X.2005.02533.x.

Kurtz S, Choudhuri JV, Ohlebusch E, Schleiermacher C, Stoye J, Giegerich R. 2001. REPuter: the manifold applications of repeat analysis on a genomic scale. Nucleic acids research, 29(22):4633-4642. DOI 10.1093/nar/29.22.4633.

Lin CS, Chen JJW, Chiu CC, Hsiao HCW, Yang CJ, Jin XH, Leebens-Mack J, de Pamphilis CW, Huang YT, Yang LH, ChangWJ, Kui L, Wong GKS, Hu JM, Wang W, Shih MC. 2017. Concomitant loss of NDH complex-related genes within chloroplast and nuclear genomes in some orchids. The Plant Journal, 90(5):994-1006. DOI 10.1111/tpj.13525.

Lin CS, Chen JJW, Huang YT, Chan MT, Daniell H, Chang WJ, Hsu CT, Liao DC, Wu FH, Lin SY, Liao CF, Deyholos MK, Wong GKS, Albert VA, Chou ML, Chen CY, Shih MC. 2015. The location and translocation of ndh genes of chloroplast origin in the Orchidaceae family. Scientific reports, 5:9040. DOI 10.1038/srep09040.

Lindley J. 1855. Folia orchidacea, an enumeration of the known species of orchids, Vol. 1. London.

Liu L, Wang Y, He P, Li P, Lee J, Soltis DE, Fu C. 2018. Chloroplast genome analyses and genomic resource development for epilithic sister genera Oresitrophe and Mukdenia (Saxifragaceae), using genome skimming data. BMC genomics, 19(1):235. DOI 10.1186/s12864-018-4633-x.

Peer) reviewing PDF | (2020:05:49446:1:1:NEW 21 Aug 2020) 
556 Neubig KM, Whitten WM, Carlsward BS, Blanco MA, Endara L, Williams NH, Moore M.

557

558

559

560

561

562

563

564

565

566

567

568

569

570

571

572

573

574

575

576

577

578

579

580

581

582

583

584

585

586

587

588

589

590

591

592

593

594

595

2009. Phylogenetic utility of $y c f l$ in orchids: a plastid gene more variable than matK. Plant Systematics and Evolution, 277(1-2):75-84. DOI 10.1007/s00606-008-0105-0.

Nguyen LT, Schmidt HA, Von Haeseler A, Minh BQ. 2015. IQ-TREE: a fast and effective stochastic algorithm for estimating maximum-likelihood phylogenies. Molecular biology and evolution, 32(1):268-274. DOI 10.1093/molbev/msu300.

Niu Z, Xue Q, Zhu S, Sun J, Liu W, Ding X. 2017. The complete plastome sequences of four orchid species: insights into the evolution of the Orchidaceae and the utility of plastomic mutational hotspots. Frontiers in plant science, 8:715. DOI 10.3389/fpls.2017.00715.

Pridgeon AM, Cribb PJ, Chase MW, Rasmussen FN. 2005. Genera Orchidacearum Volume 4: Epidendroideae, Oxford University Press.

Raubeson LA, Peery R, Chumley TW, Dziubek C, Fourcade HM, Boore JL, Jansen RK. 2007. Comparative chloroplast genomics: analyses including new sequences from the angiosperms Nuphar advena and Ranunculus macranthus. BMC genomics, 8(1):174. DOI 10.1186/1471-2164-8-174.

Rolland N, Dorne AJ, Amoroso G, Sültemeyer DF, Joyard J, Rochaix JD. 1997. Disruption of the plastid $y c f 10$ open reading frame affects uptake of inorganic carbon in the chloroplast of Chlamydomonas. The EMBO Journal, 16(22):6713-6726. DOI 10.1093/emboj/16.22.6713.

Roma L, Cozzolino S, Schlüter PM, Scopece G, Cafasso D. 2018. The complete plastid genomes of Ophrys iricolor and O. sphegodes (Orchidaceae) and comparative analyses with other orchids. PloS one. 13:e0204174. DOI 10.1371/journal.pone.0204174.

Ronquist F, Teslenko M, Van Der Mark P, Ayres DL, Darling A, Höhna S, Larget B, Liu L, Suchard MA, Huelsenbeck JP, 2012. MrBayes 3.2: efficient Bayesian phylogenetic inference and model choice across a large model space. Systematic biology, 61(3):539-542. DOI 10.1093/sysbio/sys029.

Rozas J, Ferrer-Mata A, Sánchez-DelBarrio JC, Guirao-Rico S, Librado P, Ramos-Onsins SE, Sánchez-Gracia A. 2017. DnaSP 6: DNA sequence polymorphism analysis of large data sets. Molecular biology and evolution, 34(12):3299-3302. DOI 10.1093/molbev/msx248.

Rumeau D, Peltier G, Cournac L. 2007. Chlororespiration and cyclic electron flow around PSI during photosynthesis and plant stress response. Plant, cell \& environment, 30(9): 1041-1051. DOI 10.1111/j.1365-3040.2007.01675.x.

Salazar GA, Cabrera LI, Madrinán S, Chase MW. 2009. Phylogenetic relationships of Cranichidinae and Prescottiinae (Orchidaceae, Cranichideae) inferred from plastid and nuclear DNA sequences. Annals of Botany, 104(3):403-416. DOI 10.1093/aob/mcn257.

Sasaki Y, Sekiguchi K, Nagano Y, Matsuno R. 1993. Chloroplast envelope protein encoded by chloroplast genome. FEBS letters, 316(1):93-98. DOI 10.1016/0014-5793(93)81743-J.

Schelkunov MI, Shtratnikova VY, Nuraliev MS, Selosse MA, Penin AA, Logacheva MD. 2015. Exploring the limits for reduction of plastid genomes: a case study of the mycoheterotrophic orchids Epipogium aphyllum and Epipogium roseum. Genome Biology and Evolution, 7(4):1179-1191. DOI 10.1093/gbe/evv019.

Peer) reviewing PDF | (2020:05:49446:1:1:NEW 21 Aug 2020) 
596

597

598

599

600

601

602

603

604

605

606

607

608

609

610

611

612

613

614

615

616

617

618

619

620

621

622

623

624

625

626

627

628

629

630

631

632

633

634

635

Shi C, Liu Y, Huang H, Xia EH, Zhang HB, Gao LZ. 2013. Contradiction between plastid gene transcription and function due to complex posttranscriptional splicing: an exemplary study of ycf15 function and evolution in angiosperms. PLoS One, 8(3):e59620. DOI 10.1093/gbe/evv019.

Shikanai T, Endo T, Hashimoto T, Yamada Y, Asada K, Yokota A. 1998. Directed disruption of the tobacco $n d h B$ gene impairs cyclic electron flow around photosystem I. Proceedings of the National Academy of Sciences, 95(16):9705-9709. DOI 10.1073/pnas.95.16.9705.

Shinozaki K, Ohme M, Tanaka M, Wakasugi T, Hayashida N, Matsubayashi T, Zaita N, Chunwongse J, Obokata J, Yamaguchi-Shinozaki K, Ohto C, Torazawa K, Meng BY, SugitaM, Deno H, Kamogashira T, Yamada K, Kusuda J, Takaiwa F, Kato A, Tohdoh N, Shimada H, Sugiura M. 1986. The complete nucleotide sequence of the tobacco chloroplast genome: its gene organization and expression. The EMBO journal, 5(9):20432049. DOI .10.1002/j.1460-2075.1986.tb04464.x.

Sosa V, Cameron KM, Angulo DF, Hernández-Hernández T. 2016. Life form evolution in epidendroid orchids: ecological consequences of the shift from epiphytism to terrestrial habit in Hexalectris. Taxon, 65(2):235-248. DOI 10.12705/652.2.

Stone J, Cribb P. 2017. LADY TANKERVILLE'S LEGACY, A History and Monographic Review of Phaius and Gastrorchis, Royal Botanic Gardens KEW.

Tamura K, Peterson D, Peterson N, Stecher G, Nei M, Kumar S. 2011. MEGA5: molecular evolutionary genetics analysis using maximum likelihood, evolutionary distance, and maximum parsimony methods. Molecular biology and evolution, 28(10):2731-2739. DOI 10.1093/molbev/msr121.

Thiel T, Michalek W, Varshney R, Graner A. 2003. Exploiting EST databases for the development and characterization of gene-derived SSR-markers in barley (Hordeum vulgare L.). Theoretical and applied genetics, 106(3):411-422. DOI 10.1007/s00122-002-1031-0.

Unruh SA, McKain MR, Lee YI, Yukawa T, McCormick MK, Shefferson RP, Smithson A, Leebens-Mack JH, Pires, J. C. 2018. Phylotranscriptomic analysis and genome evolution of the Cypripedioideae (Orchidaceae). American journal of botany, 105(4):631-640. DOI 10.1002/ajb2.1047.

Wang D, Zhang Y, Zhang Z, Zhu J, Yu J. 2010. KaKs_Calculator 2.0: a toolkit incorporating gamma-series methods and sliding window strategies. Genomics, proteomics \& bioinformatics, 8(1):77-80. DOI 10.1016/S1672-0229(10)60008-3.

Wick RR, Schultz MB, Zobel J, Holt KE. 2015. Bandage: interactive visualization of de novo genome assemblies. Bioinformatics. 31:3350-3352. DOI 10.1093/bioinformatics/btv383.

Wolfe KH, Li WH, Sharp PM. 1987. Rates of nucleotide substitution vary greatly among plant mitochondrial, chloroplast, and nuclear DNAs. Proceedings of the National Academy of Sciences, 84(24):9054-9058. DOI 10.1073/pnas.84.24.9054.

Wyman SK, Jansen RK, Boore JL. 2004. Automatic annotation of organellar genomes with DOGMA. Bioinformatics, 20(17):3252-3255. DOI 10.1093/bioinformatics/bth352. 
636 Xiang XG, Jin WT, Li DZ, Schuiteman A, Huang WC, Li JW, Jin XH, Li ZY. 2014.

637 Phylogenetics of tribe Collabieae (Orchidaceae, Epidendroideae) based on four chloroplast

638 genes with morphological appraisal. PloS one, 9(1):e87625. DOI

639 10.1371/journal.pone.0087625.

640 Xie WQ, Jäger K, Potts M. 1989. Cyanobacterial RNA polymerase genes rpoC1 and rpoC2

641 correspond to rpoC of Escherichia coli. Journal of bacteriology, 171(4):1967-1973. DOI

$642 \quad 10.1128 / \mathrm{jb} .171 .4 .1967-1973.1989$.

643 Yamori W, Shikanai T. 2016. Physiological functions of cyclic electron transport around

644 photosystem I in sustaining photosynthesis and plant growth. Annual review of plant biology,

645 67:81-106. DOI 10.1146/annurev-arplant-043015-112002.

646

647

Yang JB, Tang M, Li HT, Zhang ZR, Li DZ. 2013. Complete chloroplast genome of the genus

648

649

650

651

652 Cymbidium: lights into the species identification, phylogenetic implications and population genetic analyses. BMC evolutionary biology, 13(1):84. DOI 10.1186/1471-2148-13-84.

Yang Z. 2007. PAML 4: phylogenetic analysis by maximum likelihood. Molecular biology and evolution, 24(8):1586-1591. DOI .10.1093/molbev/msm088.

Yang Z, Nielsen R. 2002. Codon-substitution models for detecting molecular adaptation at individual sites along specific lineages. Molecular biology and evolution, 19(6):908-917. DOI

654 10.1093/oxfordjournals.molbev.a004148.

Yuan Y, Jin X, Liu J, Zhao X, Zhou J, Wang X, Wang D, Lai CJS, Xu W, Huang JW, HuangLP, Liu DH, Ma X, Wang L,Zhou MY, Jiang Z, Meng HB, Peng HS, Liang YT, Li RQ, Jiang C, Zhao YY, Nan, TG, Jin Y, Zhan,ZL, Yang J, Jiang WK, Huang LQ. 2018. The Gastrodia elata genome provides insights into plant adaptation to heterotrophy. Nature communications, 9(1):1-11. DOI 10.1038/s41467-018-03423-5.

Yukawa T, Ishida G. 2008. Phylogeny and systematics of Calanthe and allied genera. Abstracts

661 retrieved from 7th Annual Meeting of Japanese Society for Plant Systematics. Abstract, 32.

Yukawa T, Cribb P. 2014. Nomenclatural changes in the genus Calanthe (Orchidaceae). Bull.

663 Singapore, 65(163). the relationships in the Calanthe alliance (Orchidaceae) in China. Molecular phylogenetics and evolution, 77:216-222. DOI 10.1016/j.ympev.2014.04.005. 
Figure 1

Plastome map of Calanthe s.l..

Genes inside the circle are transcribed clockwise, and those outside are transcribed counterclockwise. Genes of different functions are color-coded. The darker gray in the inner circle shows the GC content, while the lighter gray shows the AT content. 


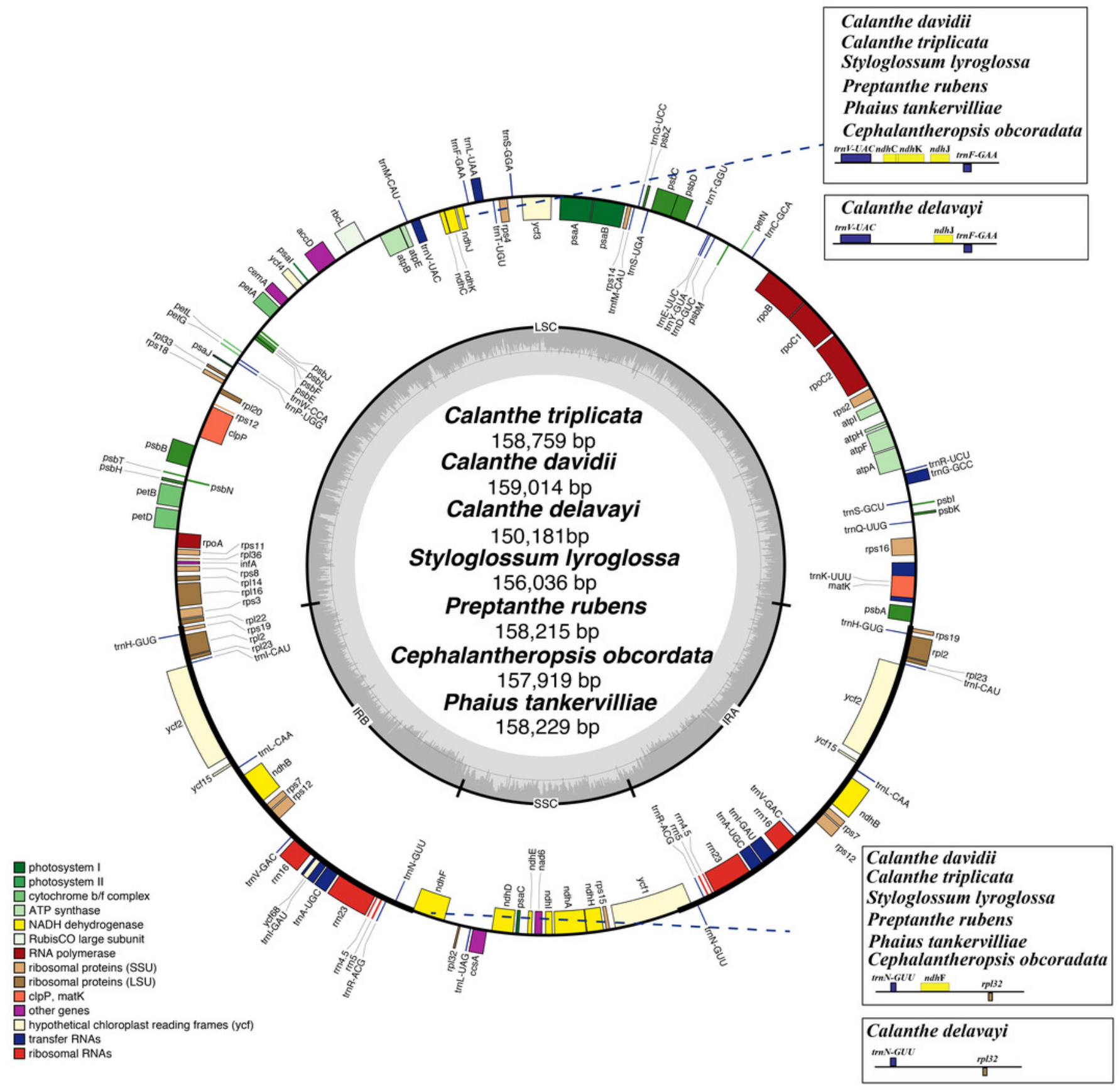


Figure 2

\section{Mauve (Multiple Alignment of Conserved Genomic Sequence With Rearrangements) alignment of platome of seven species of Calanthe s.I..}

The Calanthe triplicata genome is shown at the top as the reference genome.

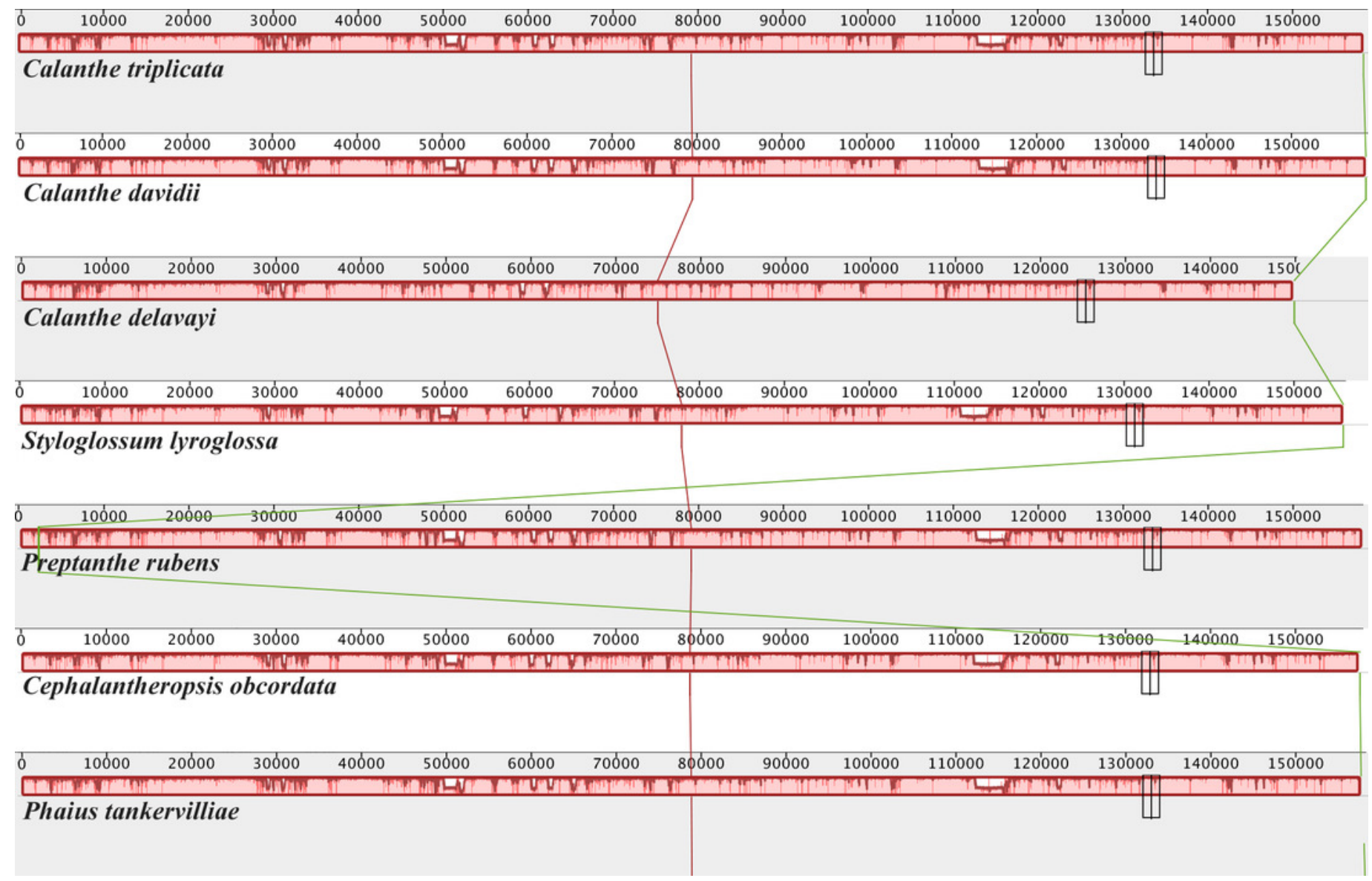




\section{Figure 3}

Comparison of seven Calanthe s.l. chloroplast genomes using mVISTA program, taking the annotation of Calanthe triplicata as a reference.

The top line shows the genes in order. A cut-off of $70 \%$ identity was used for the plots and the Y-scale represents the percent identity between 50 and 100\%. Genome regions are colorcoded as exon and conserved non-coding sequences (CNS).

Calanthe triplicata Calanthe davidii

Calanthe delavayi Phaius tankervilliae

Cephalantheropsis obcordata Styloglossum lyroglossa

Preptanthe rubens
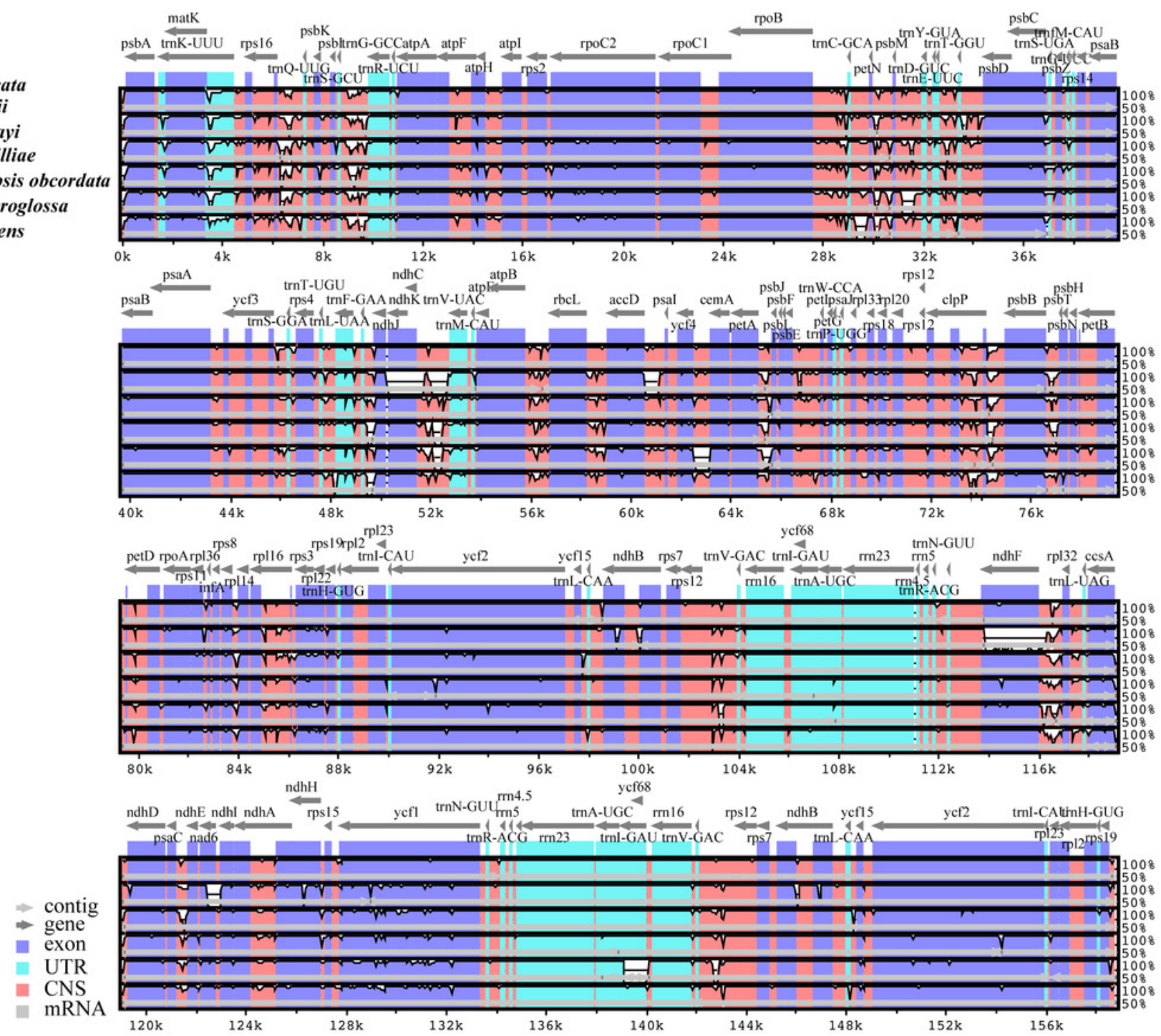
Figure 4

Comparison of nucleotide diversity $(\pi)$ values among the seven Calanthe s.l..

(A) The protein coding sequences (CDS) and intergenic spacers (IGS); (B) Sliding window analysis of the whole plastome of seven species.

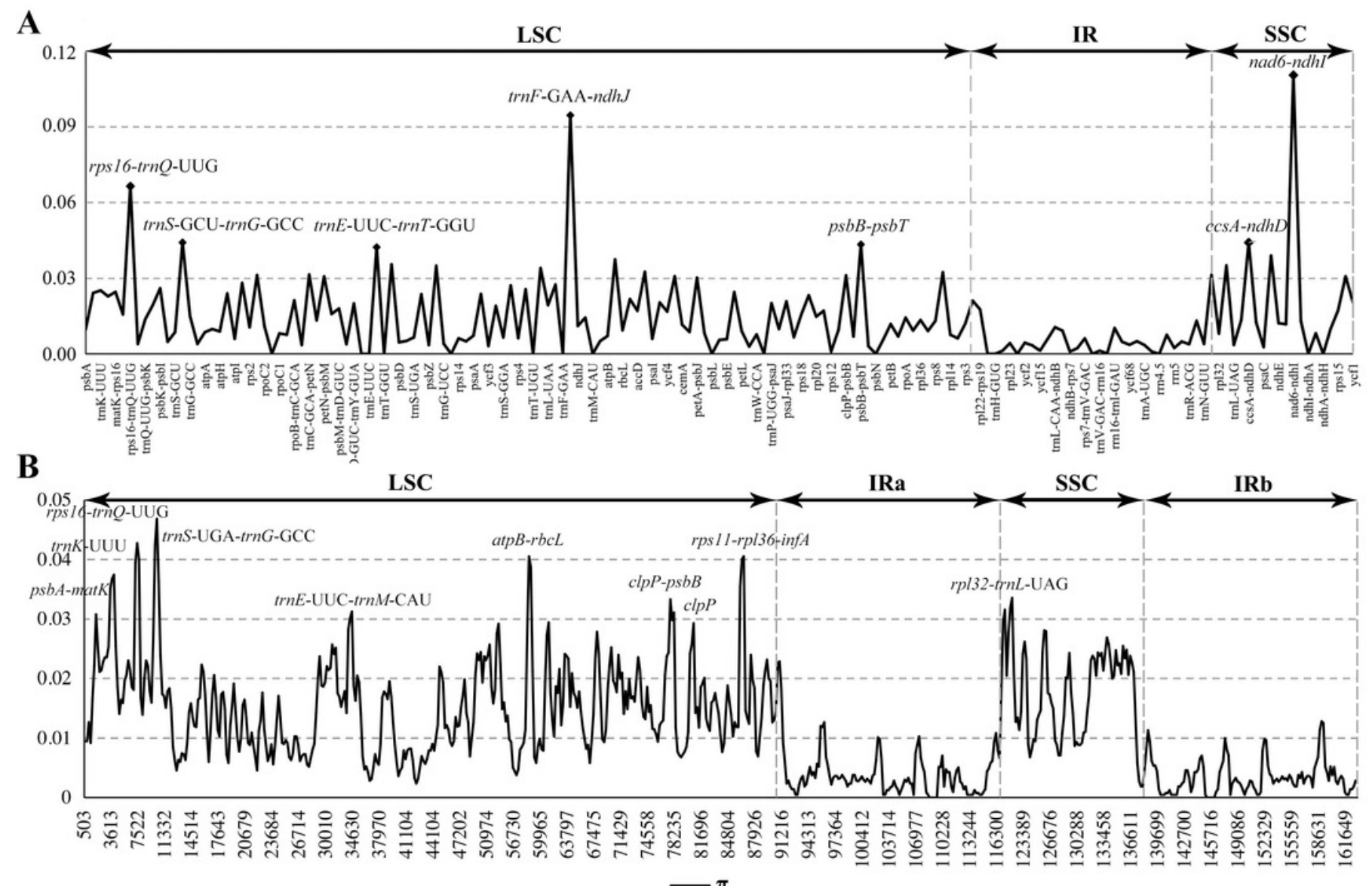


Figure 5

Comparison of the borders of LSC, SSC, and IR regions in seven Calanthe s.I. complete chloroplast genomes.

JLB (IRb /LSC), JSB (IRb/SSC), JSA (SSC/IRa) and JLA (IRa/LSC) denote the JSs between each corresponding region in the genome.

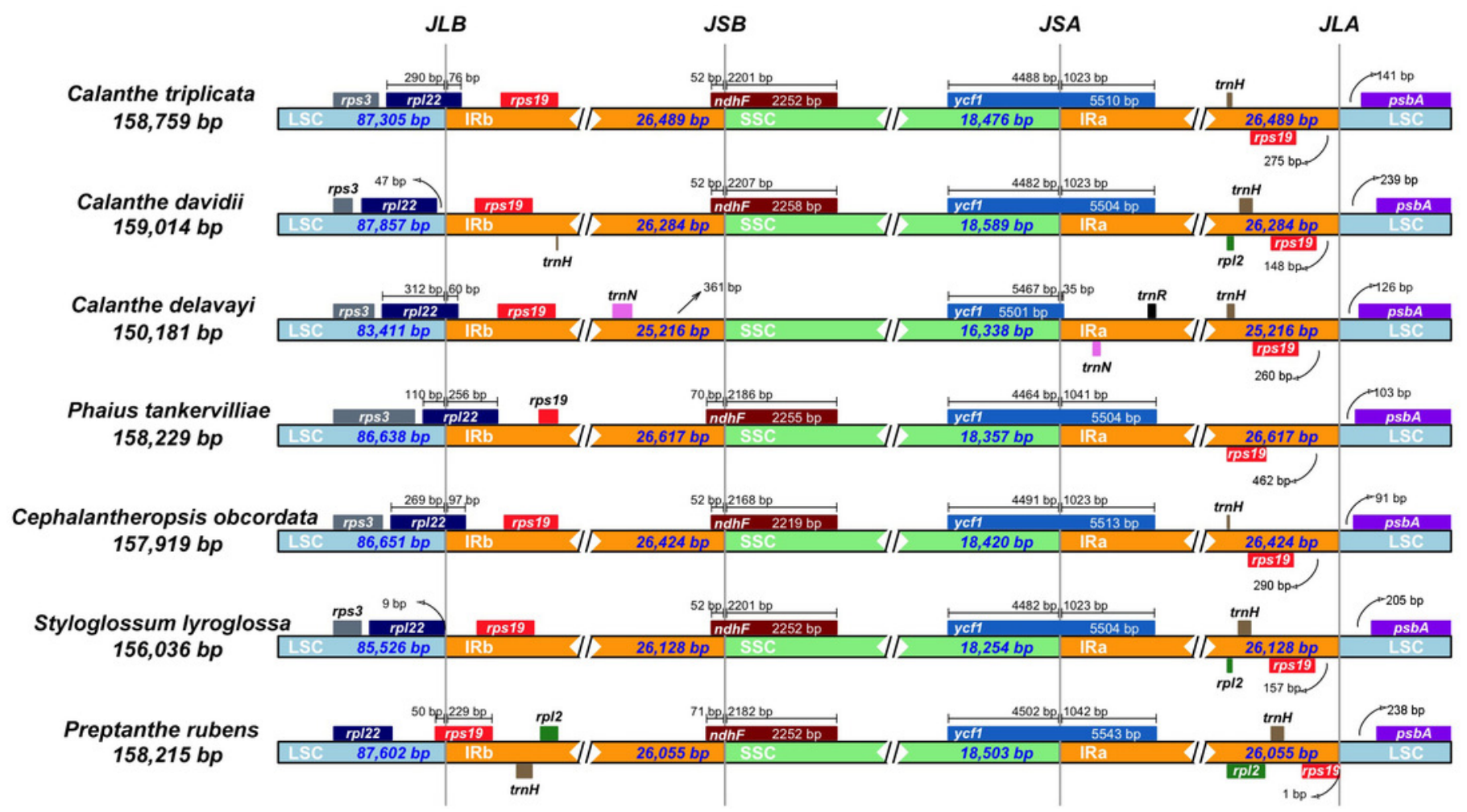




\section{Figure 6}

Maps of repeat sequence analyses, repeat sequence in seven Calanthe s.l. species chloroplast genome.

(A) Classification of SSRs by repeat type. mono-, mononucleotides; di-, dinucleotides; tri-, trinucleotides; tetra-,tetranucleotides; penta-, pentanucleotides; and hexa-, hexanucleotides. compound-, compound formation. (B) Classification of SSRs in seven species. IGS, intergenic spacer; CDS, coding sequence, CDS-IGS, part in CDS and part in IGS. (C) Number of the four repeat types, F, P, R, and $C$, indicate the long repeat type ( $F$ : forward, $P$ : palindrome, $R$ : reverse, and C: complement, respectively). (D) SSRs locus distribution among three different regions. 


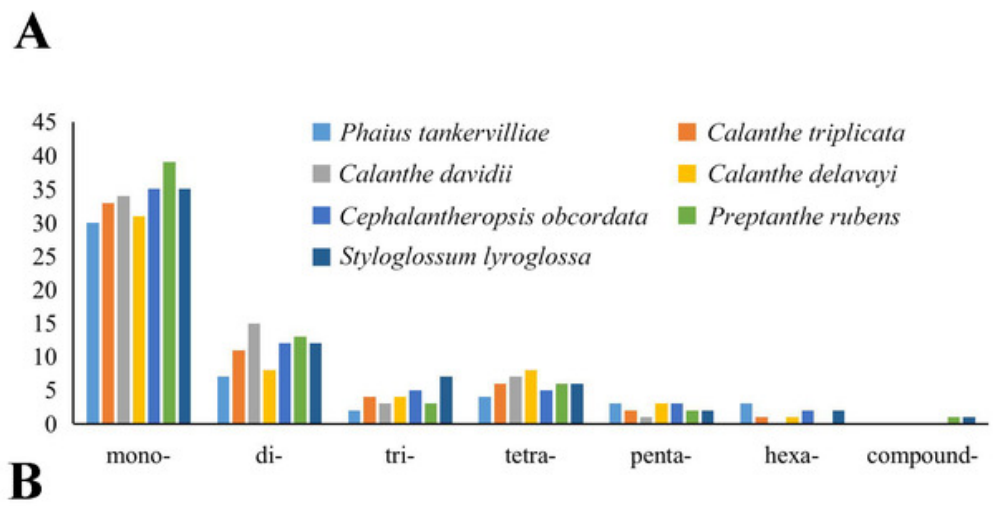

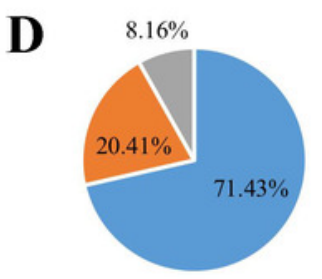

Phaius tankervilliae

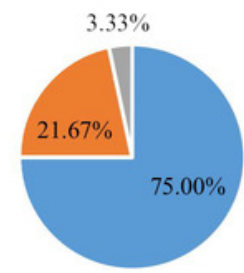

Calanthe davidii

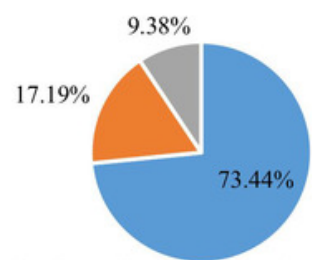

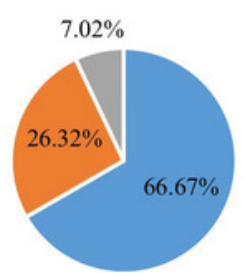

Calanthe triplicata

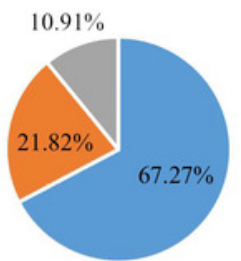

Calanthe delavayi

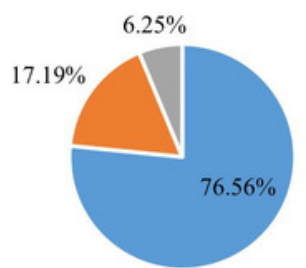

Cephalantheropsis obcordata Preptanthe rubens

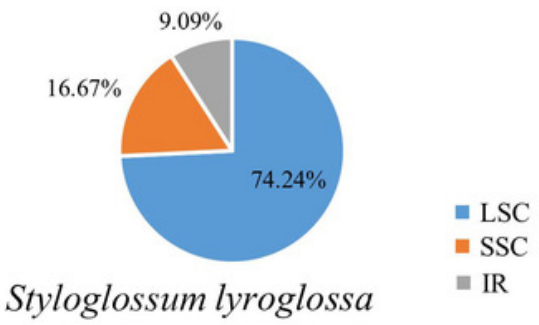


Figure 7

The $\mathrm{Ka} / \mathrm{Ks}$ ratio of 76 protein-coding genes of seven Calanthe s.l. plastomes.

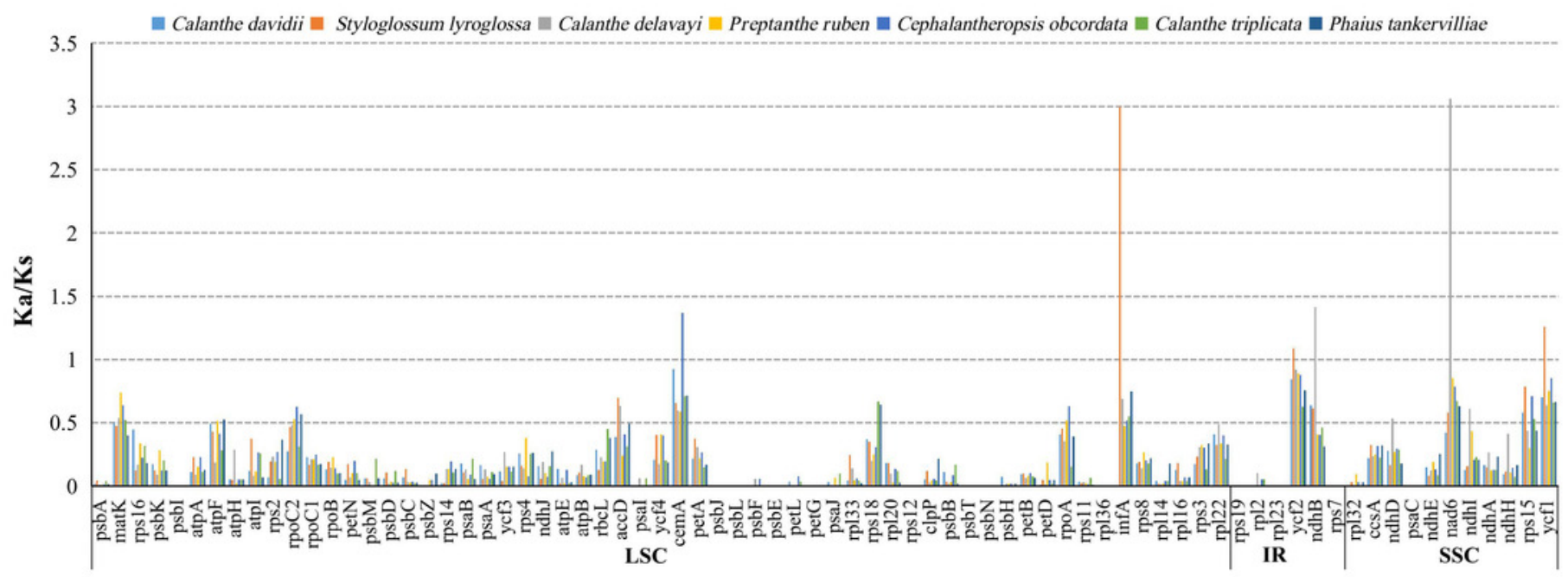


Figure 8

Phylognetic relationships of the seven Calanthe s.I. taxon constructed by four DNA data sets.

Including (A) whole plastome sequences, $(B)$ coding regions, $(C)$ intergeneric regions, and the (D) 13 highly variable regions concatenation with Maximum likelihood (ML), and Bayesian inferencee (BI) methods. ML topology shown with ML bootstrap support value/Bayesian posterior probability listed at each node.
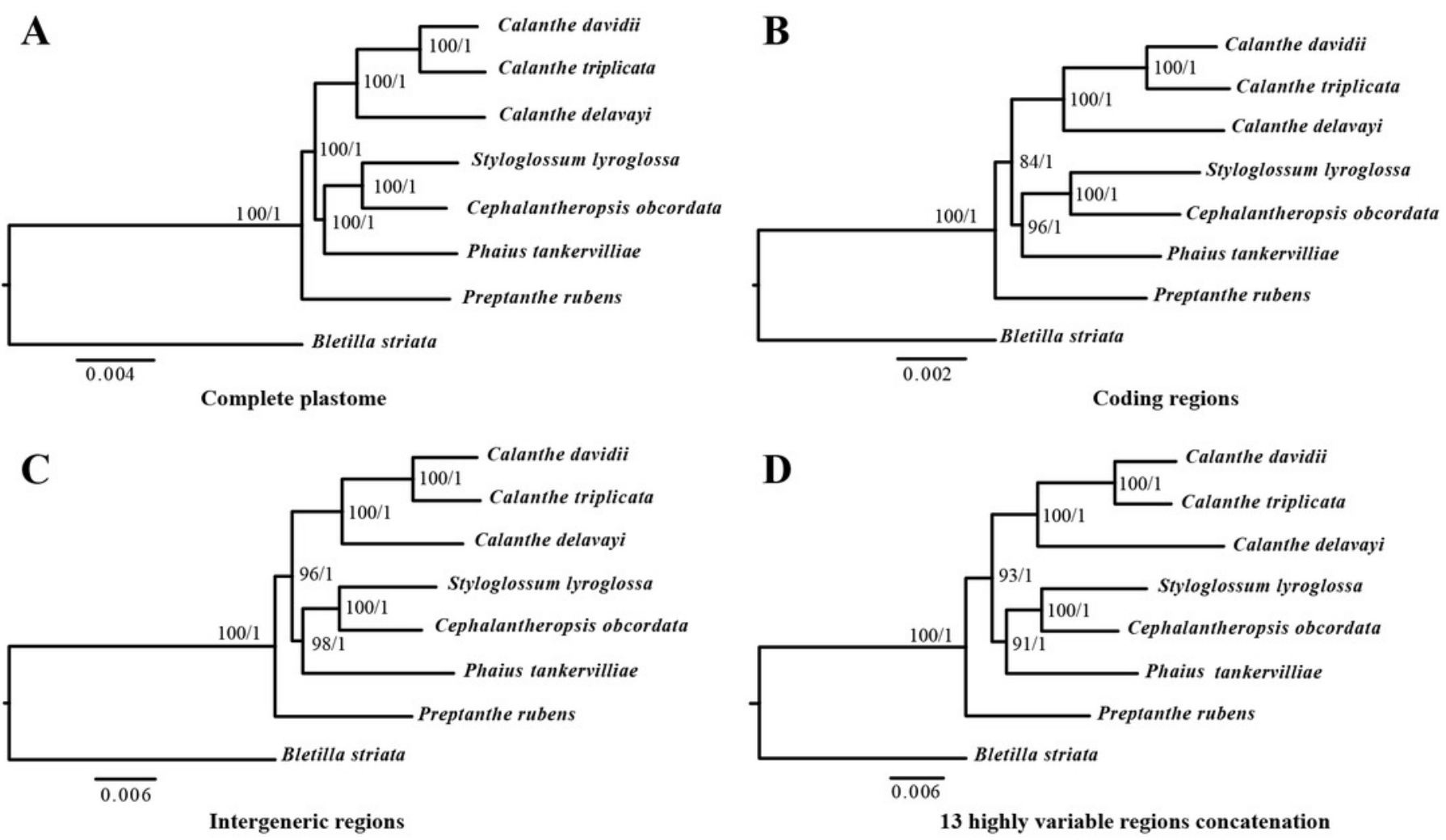


\section{Table $\mathbf{1}$ (on next page)}

The basic characteristics of the plastome of eight Calanthe s.I. species. 
1 Table 1 The basic characteristics of the plastome of eight Calanthe s.l. species.

\begin{tabular}{|c|c|c|c|c|c|c|c|c|}
\hline Species & $\begin{array}{l}\text { Calanthe } \\
\text { triplicata }\end{array}$ & $\begin{array}{l}\text { Calanthe } \\
\text { davidii (D1) }\end{array}$ & $\begin{array}{l}\text { Calanthe } \\
\text { davidii }(\mathrm{D} 2)\end{array}$ & $\begin{array}{l}\text { Calanthe } \\
\text { delavayi }\end{array}$ & $\begin{array}{l}\text { Phaius } \\
\text { tankervilliae }\end{array}$ & $\begin{array}{l}\text { Cephalantheropsis } \\
\text { obcordata }\end{array}$ & $\begin{array}{l}\text { Styloglossum } \\
\text { lyroglossa }\end{array}$ & $\begin{array}{l}\text { Preptanthe } \\
\text { rubens }\end{array}$ \\
\hline Accession number & KF753635 & MG925365 & MN708353 & MK388860 & MN708349 & MN708351 & MN708350 & MN708352 \\
\hline Genome size(bp) & 158,759 & 153,629 & 159,014 & 150,181 & 158,229 & 157,919 & 156,036 & 158,215 \\
\hline LSC length(bp) & 87,305 & 86,045 & 87,857 & 83,411 & 86,638 & 86,650 & 85,421 & 87,498 \\
\hline SSC length(bp) & 18,476 & 15,672 & 18,589 & 16,338 & 18,357 & 18,420 & 18,149 & 18,397 \\
\hline IR length(bp) & 26,489 & 25,956 & 26,284 & 25,216 & 26,617 & 26,424 & 26,233 & 26,160 \\
\hline Coding(bp) & 79,578 & 72,495 & 79,572 & 73,731 & 79,671 & 79,609 & 79,109 & 79,208 \\
\hline Non-Coding(bp) & 79,181 & 81,134 & 79,442 & 76,450 & 78,558 & 78,310 & 76,927 & 79,007 \\
\hline Number of genes & $136(115)$ & $136(115)$ & $136(115)$ & $133(112)$ & $136(115)$ & $136(115)$ & $136(115)$ & $136(115)$ \\
\hline Number of protein-coding genes & $88(80)$ & $88(80)$ & $88(80)$ & $85(77)$ & $88(79)$ & $88(80)$ & $86(79)$ & $86(79)$ \\
\hline Number of tRNA genes & $38(30)$ & $38(30)$ & $38(30)$ & $38(30)$ & $38(30)$ & $38(30)$ & $38(30)$ & $38(30)$ \\
\hline Number of rRNA genes & $8(4)$ & $8(4)$ & $8(4)$ & $8(4)$ & $8(4)$ & $8(4)$ & $8(4)$ & $8(4)$ \\
\hline GC content $(\%)$ & 36.70 & 36.90 & 36.60 & 36.90 & 37.00 & 36.80 & 36.90 & 36.70 \\
\hline GC content in LSC $(\%)$ & 34.40 & 34.50 & 34.40 & 34.50 & 34.80 & 34.50 & 34.60 & 34.30 \\
\hline $\mathrm{GC}$ content in $\mathrm{SSC}(\%)$ & 29.70 & 30.20 & 29.60 & 29.40 & 29.90 & 29.70 & 29.90 & 29.70 \\
\hline GC content in IR (\%) & 43.00 & 43.10 & 43.10 & 43.30 & 43.00 & 43.10 & 43.10 & 43.30 \\
\hline
\end{tabular}




\section{Table 2 (on next page)}

Genes length (bp) difference between two versions of Calanthe davidii complete plastome. 
1 Table 2 Genes length (bp) difference between two versions of Calanthe davidii complete plastome.

\begin{tabular}{llllllllll}
\hline Version & nad6 & $n d h A$ & $n d h C$ & $n d h D$ & $n d h E$ & $n d h F$ & $n d h I$ & $n d h K$ & $y c f 2$ \\
\hline D1 (MG925365) & 120 & 869 & 171 & 987 & 306 & 1,827 & 297 & 138 & 4,650 \\
D2 (MN708353) & 531 & 2,215 & 363 & 1,509 & 321 & 2,259 & 504 & 774 & 6,813 \\
\hline
\end{tabular}

2 


\section{Table 3(on next page)}

Gene contents in seven Calanthe s.l. species plastomes. 
1 Table 3 Gene contents in seven Calanthe s.l. species plastomes.

Classfication Genes

Genetic apparatus

Large ribosomal subunits $r p l 2 *(\times 2)$, rpl14, rpl16*, rpl20, rpl22, rpl23(×2), rpl32, rpl33, rpl36 Small ribosomal subunits $\begin{aligned} & r p s 2, r p s 3, r p s 4, \\ & r p s 19(\times 2)\end{aligned}$

RNA polymerase

subunits

гро $A$, rроB, $г$ росC1*, гроC2

DNA dependent RNA

polymerase Protease

clpP**

Maturase

matK

Ribosomal RNAs $\quad r r n 4.5(\times 2), r r n 5(\times 2), r r n 23(\times 2), r r n 16(\times 2)$

$\operatorname{trn} A$-UGC $(\times 2) *, \operatorname{trn} C$-GCA, $\operatorname{trn} D$-GUC, $\operatorname{trn} E-\mathrm{UUC}, \operatorname{trn} F$-GAA, $\operatorname{trnfM}$-CAU, $\operatorname{trn} G-$ GCC, $\operatorname{trn} G-\mathrm{UCC} *$, $\operatorname{trn} H-\mathrm{GUG}(\times 2)$, $\operatorname{trn} I-\mathrm{CAU}(\times 2), \operatorname{trn} H-\mathrm{GUG}, \operatorname{trn} I-\mathrm{GAU}(\times 2) *, \operatorname{trnK}-$

Transfer RNAs $\mathrm{UUU} *, \operatorname{trn} L-\mathrm{CAA}(\times 2), \operatorname{trn} L-\mathrm{UAG}, \operatorname{trn} L-\mathrm{UUA} *$, trnM-CAU, $\operatorname{trn} N-\mathrm{GUU}(\times 2)$, $\operatorname{trn} P-$ UGG, $t r n Q$-UUG, $t r n R$-ACG $(\times 2), t r n R$-UCU, $t r n S$-GCU, $t r n S$-GGA, $t r n S$-UGA, $t r n T$ GGU, $\operatorname{trn} V$-GAC $(\times 2), \operatorname{trn} V$-UAC*, $\operatorname{trn} W$-CCA, $\operatorname{trn} Y$-GUA

Light dependent

photosynthesis

Photosystem I psaA, psaB, psaC, psaI, psaJ, ycf3**, ycf4

Photosystem II

$p s b A, p s b B, p s b C, p s b D, p s b E, p s b F, p s b H, p s b I, p s b J, p s b K, p s b L, p s b M, p s b N, p s b T$, $p s b Z$

$\mathrm{NAD}(\mathrm{P}) \mathrm{H}$ dehydrogenase complex

$n d h A *, n d h B *(\times 2), n d h C_{\dagger}^{\dagger}, n d h D, n d h E, n d h F \dagger, n d h G, n d h H, n d h I, n d h J, n d h K_{\dagger}^{\dagger}$

F-type ATP synthase $\quad$ atp $A$, atp $B$, atp E, atpF*, atpH, atpI

Cytochrome b6/f complex petA, petB*,petD*,pet $G, \operatorname{pet} L, \operatorname{pet} N$

Light independent

photosynthesis

Inner membrane protein cemA

Cytochrome $\mathrm{C}$ biogenesis

protein

$\operatorname{ccs} A$

Large subunit of Rubisco $r b c L$ 
Subunit of acetyl-CoA- $a c c D$
carboxylase

Translation initiation

factor

$\operatorname{infA}$

Function uncertain $\quad y c f 1, y c f 2(\times 2), y c f 15(\times 2), y c f 68(\times 2)$

$2 *$ Gene containing one intron, $* *$ gene containing two introns, a trans-splinting gene, $(\times 2)$ shows genes have two

3 copies, †ंgene lost in C. delavayi.

4 
Table 4 (on next page)

The polymorphic simple sequence repeats in Calanthe s.I. plastomes. 
1 Table 4 The polymorphic simple sequence repeats in Calanthe s.l. plastomes.

\begin{tabular}{|c|c|c|c|}
\hline Type & $\begin{array}{l}\text { C. triplicata/C. davidii/C. delavayi/S. } \\
\text { lyroglossa/P. rubens } / \text { C. obcordata } / P \text {. } \\
\text { tankervilliae }\end{array}$ & Location & Region \\
\hline AT & $6 / 6 / 0 / 6 / 0 / 0 / 0$ & rpoB-trnC-GCA & LSC \\
\hline AT & $7 / 7 / 0 / 0 / 5 / 0 / 0$ & trnE-UUC-trnT-GGU & LSC \\
\hline AT & $0 / 0 / 7 / 6 / 5 / 7 / 0$ & $\operatorname{trnL}$-UAA-trnF-GAA & LSC \\
\hline AT & $0 / 0 / 7 / 6 / 0 / 7 / 0$ & trnL-UAA-trnF-GAA & LSC \\
\hline GA & $5 / 5 / 5 / 0 / 5 / 5 / 5$ & $y c f 2$ & IR \\
\hline TA & $5 / 7 / 0 / 5 / 0 / 6 / 0$ & $p s b B-p s b T$ & LSC \\
\hline TA & $5 / 5 / 0 / 0 / 6 / 0 / 0$ & $n d h F-r p l 32$ & $\mathrm{SSC}$ \\
\hline TA & $0 / 0 / 8 / 5 / 5 / 0 / 5$ & $c l p P-p s b B$ & LSC \\
\hline TC & $5 / 5 / 5 / 0 / 5 / 5 / 5$ & $y c f 2$ & IR \\
\hline TG & $5 / 5 / 5 / 0 / 5 / 5 / 5$ & rpl33-rps 18 & LSC \\
\hline AAT & $4 / 4 / 4 / 4 / 0 / 4 / 0$ & $p s a C-n d h E$ & $\mathrm{SSC}$ \\
\hline AGAA & $0 / 0 / 3 / 0 / 3 / 3 / 0$ & psbM-trnD-GUC & LSC \\
\hline AATG & $0 / 3 / 3 / 3 / 0 / 3 / 0$ & сетA & LSC \\
\hline ATTA & $3 / 3 / 0 / 3 / 3 / 0 / 0$ & psaJ-rpl33 & LSC \\
\hline GTCT & $3 / 3 / 3 / 3 / 0 / 3 / 3$ & $\operatorname{atp} A$ & LSC \\
\hline TTGA & $3 / 3 / 3 / 3 / 0 / 3 / 3$ & $n d h E$ & $\mathrm{SSC}$ \\
\hline ATCTT & $3 / 3 / 0 / 0 / 3 / 3 / 3$ & $p s b K-p s b I$ & LSC \\
\hline ACAAA & $3 / 0 / 0 / 0 / 0 / 3 / 3$ & $n d h C-t r n V$-UAC & LSC \\
\hline
\end{tabular}

